\title{
Advances
}

Alessandro Di Nola' / Georgi Kocharkov² / Aleksandar Vasilev ${ }^{3}$

\section{Envelope wages, hidden production and labor productivity}

\author{
${ }^{1}$ University of Konstanz, Konstanz, Germany, E-mail: alessandro.di-nola@uni-konstanz.de \\ ${ }^{2}$ Coethe University Frankfurt and Deutsche Bundesbank, Frankfurt am Main, Germany \\ ${ }^{3}$ University of Licoln, Lincoln, UK
}

\begin{abstract}
:
We evaluate the relative importance of aggregate labor productivity versus income taxes and social contributions for tax compliance in an economy with a large degree of informality. Empirical evidence points out that tax evasion in Europe happens through partially concealing wages and profits in formally registered enterprises. To this end, we build a model in which employer-employee pairs of heterogeneous productive capacities make joint decisions on the degree of tax evasion. The quantitative model is used to analyze the case of Bulgaria which has the largest informal economy in Europe and underwent a number of important tax reforms over the period 2000-2014, including the introduction of a flat income tax in 2008. The estimation strategy relies on matching the empirical series for the size of the informal economy and other aggregate outcomes for 20002014. Our counterfactual experiments show that the most important factor for the changing size of the informal economy is labor productivity, which accounts for more than $75 \%$ of the change. The variation in corporate income tax accounts for the rest. We find that the 2008 flat tax reform did not play any visible role in coping with informality.
\end{abstract}

Keywords: envelope wages, flat tax reform, hidden production, informal economy

JEL classification: H24, H25, H26, C63, E62, E65

DOI: 10.1515/bejm-2018-0252

\section{Introduction}

\begin{abstract}
Informal economic activity is a pervasive phenomenon worldwide. ${ }^{1}$ Moreover, informal production is present not only in developing countries but also in emerging and developed economies. Informality is well-spread in Eastern and Southern Europe and reaches its highest in Bulgaria where the informal production amounts to a third of officially reported GDP in the late 2000s, as shown in Figure 1A. ${ }^{2}$

According to the 2013 World Bank Enterprise Survey almost all firms in Europe, and in particular in Bulgaria, are officially registered. ${ }^{3}$ These firms conceal part of their economic activity to avoid paying taxes and social contributions. However, the number of their employees is not underreported. The 2013 Eurobarometer survey on undeclared work confirms this statement. Figure 1B presents the share of employees with no formal contracts. The average share across Europe is $2 \%$, however, in Bulgaria it is $0 \%$. Informal production, in this context, amounts to misreporting wages and profits to the tax authorities. Williams (2008), among others, emphasizes the pervasive practice of firms reporting lower official wages and compensating their employees with informal payments, known as "envelope wages". The share of workers with envelope wages is almost at its peak in Bulgaria at 10\% according to the Eurobarometer surveys in 2007-2013 (see Figure 1C). Only Romania has a higher share of $15 \%$. The followers in the European ranking are Hungary, Italy and Spain with about $5-7 \%$. Note that the average share of workers with envelope wages for the European Union is 4\% in 2007-2013. Finally, the reported fraction of income received in envelope wages in Bulgaria of $43 \%$ is also at the high end of the distribution (see Figure 1D). In the Eurobarometer surveys, workers self-report whether they receive informal payments or not. These results are likely to underestimate the occurrence of envelope wage practices since respondents are usually not comfortable to confess to tax evasion. Therefore, the numbers in Figure $1 \mathrm{C}$ and Figure 1D can be viewed as a lower bound (see Online Appendix A.1 for further details on envelope wages).
\end{abstract}


A

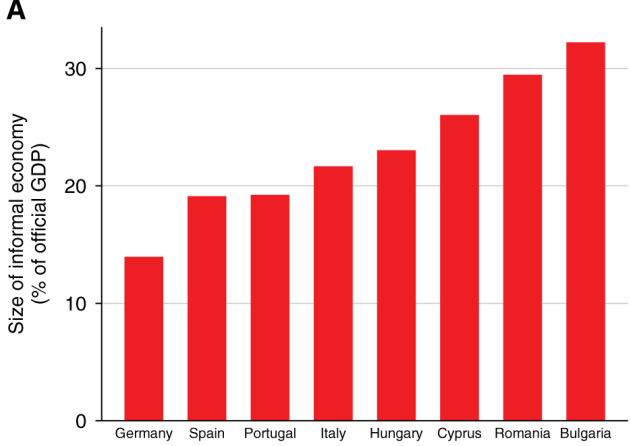

C

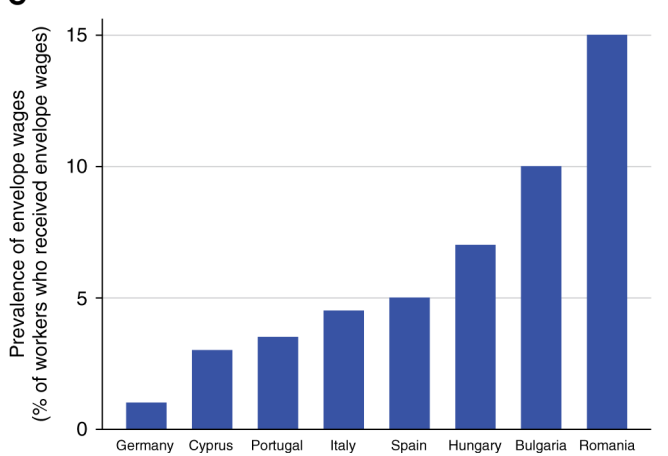

B

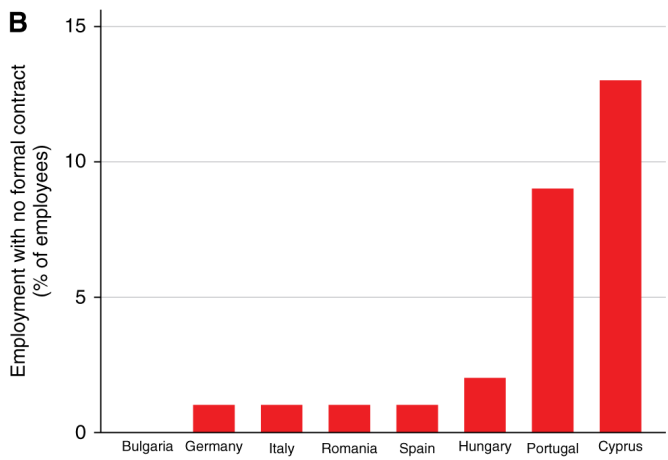

D

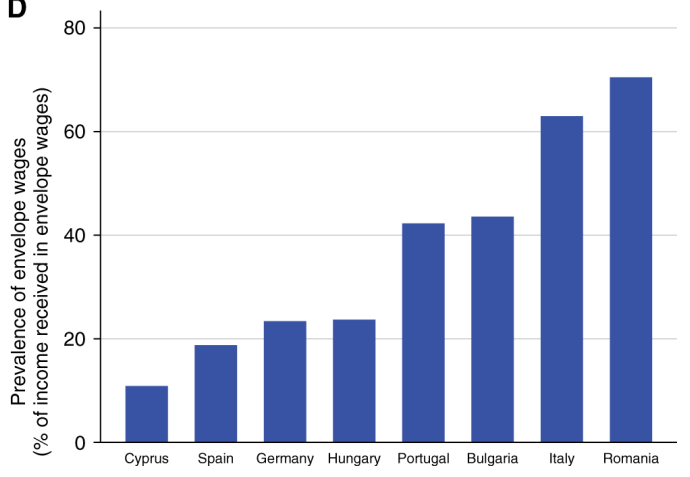

Figure 1: Economic informality in Europe, 2007-2013. (A) Informal Economies (B) No Formal Contracts (C) Envelope Wages (\% of Workers) (D) Envelope Wages (\% of Income).

Notes: The size of the informal economy is taken from Schneider and Enste (2013). The share of employees with no formal contracts is derived from the 2013 Eurobarometer survey (Special Eurobarometer 402). The share of workers with envelope wages and the share of income received in envelope wages are derived from 2007 to 2013 Eurobarometer surveys (Special Eurobarometer 284 and 402). A detailed description of the data used in all figures and tables is presented in Online Appendices A.1 and A.2.

The Bulgarian economy underwent a number of significant changes in the last 15 years (2000-2014). The informal economy size shrank from $37 \%$ of official GDP to $31 \%$. At the same time the observed aggregate labor productivity (GDP per employee) rose by around 45\%. Furthermore, several major tax reforms were implemented in this time period which reduced the average tax burden levied on both workers and firms. The corporate income tax rate went from $32.5 \%$ in 2000 to $10 \%$ in 2008 . The progressivity of the personal income tax was gradually reduced in the 2000-2007 period and finally eliminated in 2008 when personal income taxes became proportional with a 10\% rate; see Section 2 for further details. An important motivation behind these tax reforms was the inherent idea that lower (and less progressive) taxes would reduce the amount of informality and tax evasion. These stylized facts suggest that the Bulgarian economy in the last two decades can be viewed as a natural laboratory to study the determinants of the informal economic activity and tax evasion practices related to it.

Our main goal in the paper is to determine the driving forces behind the observed changes in the informal economy using Bulgaria as a case study. ${ }^{4}$ We start from the premise that envelope wage practices are the predominant source of informal (hidden) production there. We explore what is the role of reducing taxes and whether different taxes have a differential effect on the informal economy. The mechanism at work is clear: when taxes are lower, tax evasion becomes less attractive. At the same time, we control for various other factors that may influence the degree of tax evasion such as institutional efficiency in tax collection and the aggregate productivity level in the economy. When aggregate productivity rises, there is more income to be hidden. However, tax evasion will rise only if the marginal benefit of hiding increases. As pointed out in the analytical part of the paper, this happens only when the tax system is progressive. In such case, rising income levels imply higher marginal tax rates and stronger incentives for evasion. On the other hand, a rise in productivity may mechanically decrease the level of informality measured as the share of official GDP. Suppose that the nominal amount of tax evasion increases little to none. However, the GDP level increases due to the higher productivity. Then, the share of informal activity out of GDP is to decrease.

Ultimately, disentangling the forces behind the observed decline in the size of the informal economy in Bulgaria for the period 2000-2014 is a quantitative question. Up to this end, we build a model suited for studying tax evasion in Bulgaria. In particular, we carefully model the prevalent practice of envelope wages/profits used for generating informal output and evading taxes. The model economy is populated by a large number of islands with different productivity levels. Each island is occupied by one-period lived employer and a 
worker who collaborate on the production of a homogeneous good. Production depends on both an aggregate productivity shock which changes over time and an island-specific productivity level. The government in the economy cannot observe the island-specific productivity on each island. This creates possibilities of tax evasion by the productive pair. When underreporting production, the employer pays the worker an official salary which should be at least as high as the prevailing minimum wage. The rest of the worker's remuneration is an unofficial undeclared salary which we dub the envelope wage. The rest of the undeclared output is appropriated by the employer as an envelope profit.

The level of underreported production in the model is pinned down by comparing the benefits of tax evasion in terms of forgone tax and social contributions payments to its costs. Hiding output reduces the overall production capacity of the pair. This reflects the adjustments of the production process due to tax evasion. For instance, double accounting practices can be costly in terms of time or concealed production may take place at night.

The quantitative implementation of the model takes as inputs the detailed tax and social contribution schemes in Bulgaria for the 2000-2014 period. The parameters of the model are estimated via a minimum distance technique. In doing so, we match the evolution of the size of the informal economy in Bulgaria for the time period of 2000-2014. Additional time series data targets utilized in the estimation are the observed aggregate labor productivity and average wages. Utilizing them, the model recovers the evolution of true productivity and workers remuneration over time. To the best of our knowledge, this is one of the few novel quantitative works on tax evasion in a European setting, that captures the prevailing tax evasion practices in Europe, and thus stands in sharp contrast with respect to the vast literature focusing on developing countries.

The performed quantitative experiments point out that the rise of productivity over the period is the main driver behind the declining informality. If we fix taxes to their 2000 level but let productivity rise as predicted by the baseline model, then this counterfactual economy generates more than $75 \%$ of the decline in informality observed in the baseline version. Tax policy is important too but plays a secondary role. Feeding observed tax and social contributions changes over the period into the model while fixing productivity to its 2000 level accounts for around $35 \%$ of the change in informality observed in the baseline economy. Among the taxes considered in the model, the most important determinant for the changing patterns of tax evasion is the corporate income tax. Social contributions and personal income taxes have no effect on the evolution of the informal economy size.

There are two main reasons why personal income tax and social contributions do not play a significant quantitative role in our model. First, they are levied on the official wages which turn out to be only a small fraction of production output. Therefore, falling tax rates on the workers' income are quantitatively much less relevant than the falling tax rates on the employers' profits. Second, tax evasion in the estimated economy occurs in production units which are relatively less productive. This happens because the estimated cost of tax evasion rises sharply with productivity. ${ }^{5}$ Therefore, the diminishing progressivity of the personal income tax over time reduces the incentives for tax evasion only in more productive units which do not evade much in first place.

We further validate the key implications of our quantitative analysis using additional empirical evidence. Specifically, we test some of the implications using data on informality, tax rates and labor productivity across countries and time and across sectors. As predicted by our structural model, these data confirm that (i) countries with stronger productivity growth have a sharper decrease in informal economy and (ii) industrial sectors with lower productivity have higher level of informality.

In a subsequent exercise, we take the model economy in 2014 and ask what are the optimal tax schedules for personal and corporate income. The Ramsey-type problem amounts to maximizing produced output and, therefore, minimizing tax evasion, which is the only factor that reduces production. At the same time, the collected tax revenue is fixed to the observed levels in the baseline model. Optimal taxation requires a mild reduction in the corporate tax and a significant rise of the personal income tax. Also, optimal personal income taxes are proportional as observed in the data for 2014. The exercise delivers one more important insight: the benefits of setting optimal taxes instead of the observed ones in terms of productive efficiency are very small.

Can our analysis can be extended to other countries? Our model framework can be easily extended to other countries where informality happens within formally registered enterprises which offer formal wage contracts to workers and where wages and profits are partially hidden. As explained above, this is the empirically relevant case in Europe. We outline a path of how to do that in Section 5.1. Our findings suggest that the effects of personal income tax and/or employees' social contributions on informality are stronger in countries where workers have more bargaining power.

What are the policy implications of these findings? Reducing personal income tax levels and/or progressivity would not have a slashing effect on tax evasion. Instead, our quantitative results point out that reforming the corporate tax code can lead to lower levels of tax evasion. More importantly, our findings emphasize that further improvements in labor productivity may be the main driver for eradicating tax evasion. This calls for 
active policies aimed at product/labor market liberalization, entry barriers removal and further investments in research and development.

The rest of the document is structured as follows. In the next Subsection 1.1, we review the current literature and its relation to our work. Section 2 presents stylized facts about informality, labor productivity and the specifics of the tax and social contributions system in Bulgaria. In Section 3 we present the economic environment. Section 4 discusses the estimation strategy and model fit. Section 5 contains the results of the counterfactual exercises, while Section 6 validates the main quantitative results using cross-country and cross-sector data on informality and labor productivity. Section 7 discusses optimal taxation. We provide conclusions in the last section.

\subsection{Related literature}

The practice of envelope wages in Europe have been studied empirically by Williams (2008), Williams and Padmore (2013), and Williams (2014) among others using data from the Eurobarameter surveys. In an innovative empirical exercise Pelek and Uysal (2016) estimate the extent of envelope wages in the case of Turkey combining data collected on a firm and household level. Tonin (2011) is the first to take into account the interaction between workers and employers in the process of tax evasion within an economic framework. Unlike us, he explores the role of minimum wage legislation for tax evasion in the case of Hungary.

A small but growing macroeconomic literature deals with the aggregate consequences of tax evasion. Chen (2003) incorporates tax evasion in an endogenous growth model, whereas Maffezzoli (2011) studies the distributional implications of income tax evasion in a heterogeneous agents framework with uninsurable income risk. In contrast to these papers, we abstract from the dynamic consequences of tax evasion but focus on the employer-worker joint decision to go informal. In addition, we incorporate in our macroeconomic model a detailed representation of different taxes which allows us to assess the relative importance of each of them for tax evasion. ${ }^{6}$

A number of macroeconomic papers apply two-sector models of formal and informal production to emerging economies. Antunes and Cavalcanti (2007) use a general equilibrium model of occupational choice and informality to emphasize the role of regulation costs and financial contracts enforcement for cross-country differences in informality. In a similar spirit, Kuehn (2014) outlines the role of taxes and government quality for the level and dispersion of informal activity in OECD countries. Orsi, Raggi, and Turino (2014) studies the determinants of the size of the informal economy for the case of Italy. Pappa, Sajedi, and Vella (2015) show that tax evasion and corruption matter for the size of fiscal multipliers. Joubert (2015) explores the link between informality and the design of a pension system within a structural model, while Albrecht, Navarro, and Vroman (2009) and Meghir, Narita, and Robin (2015) study the interaction between informality and labor market dynamics. Koreshkova (2006) evaluates the role of inflation as an implicit tax on the informal economy. Note that the two-sector setup used in these papers implies that informality never takes place in formally registered firms. Therefore, this approach is not entirely suited to study the observed envelope wage practices in Europe. Ulyssea (2018) extends the existing literature that models informality as a binary choice introducing an intensive margin, which implies that formal firms can hire workers "off the books". We relate to Ulyssea (2018) in the sense that we also focus on the intensive margin but we depart from his analysis in two crucial aspects. First, we abstract altogether from the extensive margin, motivated by the empirical evidence pointing out that in Europe most firms are registered. ${ }^{7}$ Second, in our setup workers are not hired "off the books" but are paid part of their wage in cash, whenever the employer and the worker decide to tax evade. We stress that this is the most relevant case: Figure 1B shows that the share of employees with no formal contracts is negligible in Bulgaria and is also quite low for other European countries (with a couple of exceptions).

On the empirical side, Gorodnichenko, Martinez-Vazquez, and Peter (2009) study the effects of the 2001 flat tax reforms in Russia on tax evasion and economic activity. The reform reduced the average taxes of the rich while leaving the tax burden for the poor unchanged. The results point out that less progressive income taxes led to a sizable decrease in tax evasion coming from the affected affluent households. In contrast, the flattening of the income tax does not have a dramatic effect on informality in our estimated model. This is so, because envelope wage practices occur in relatively poor households who are unaffected by the flat tax reform. Using tax data from a field experiment in Denmark, Kleven et al. (2011) document that tax evasion differs greatly depending on the sources of income: in particular, tax compliance is much lower for income that is not subject to third-party reporting, like self-employed or business income. In our paper we abstract from the self-employed who are not subject to third-party reporting and thus can evade. ${ }^{8}$ We focus more on salaried workers and companies. In Bulgaria, the share of self-employed out of the total labor forced is quite low: it was $12.5 \%$ in 2014, the last year of our sample, compared to an EU average of 16.5\%. Table A.3 in Online Appendix A.1 shows that Eastern European countries have relatively low share of self-employed workers. 
Our approach has two main advantages over an empirically-driven analysis based on a quasi-experimental setup. First, we can recover the parameters of the model using only time series variations in aggregate productivity, tax rates and informal economy size. This is a huge advantage when detailed micro-data are not available. Second, the model allows us to separate the relative strengths of several driving forces behind informality and tax evasion. This can be done in the quantitative framework by explicitly shutting down one or several of these driving forces at a time. Therefore, we have a say on how important are changes in taxation versus changes in productivity in shaping the informal economic activities. Moreover, we can distinguish the role of changing different taxes in coping with tax evasion practices.

\section{Facts and Institutional design}

The Bulgarian economy was in transition from planning to market in the 1990s. Therefore, here we focus on the subsequent period. We start our analysis in 2000 , just three years after the introduction of the currency board in Bulgaria which stabilized the macroeconomic environment. In what follows, we summarize the evolution of the Bulgarian informal economy and its potential determinants in the period 2000-2014.

\subsection{Informal economy, labor productivity and institutional efficiency}

The size of the informal economy in Bulgaria decreased by around 7 percentage points (from $37 \%$ of the official GDP to 31\%) in the period 2000-2014. Figure 2 presents this decline along with the corresponding $45 \%$ rise in labor productivity (computed as GDP per employee) in this period. The dotted line in 2008 marks both the start of the Great Recession, which arrived a year later in Bulgaria, and the introduction of the flat tax personal income schedule. In the period 2008-2010 informality slightly increased, while observed productivity decreased (due to the Great Recession). As already mentioned, one of the main goals of this paper is to disentangle the role of economic development and productivity growth from the effects of tax reforms for the level of tax evasion and informal production.

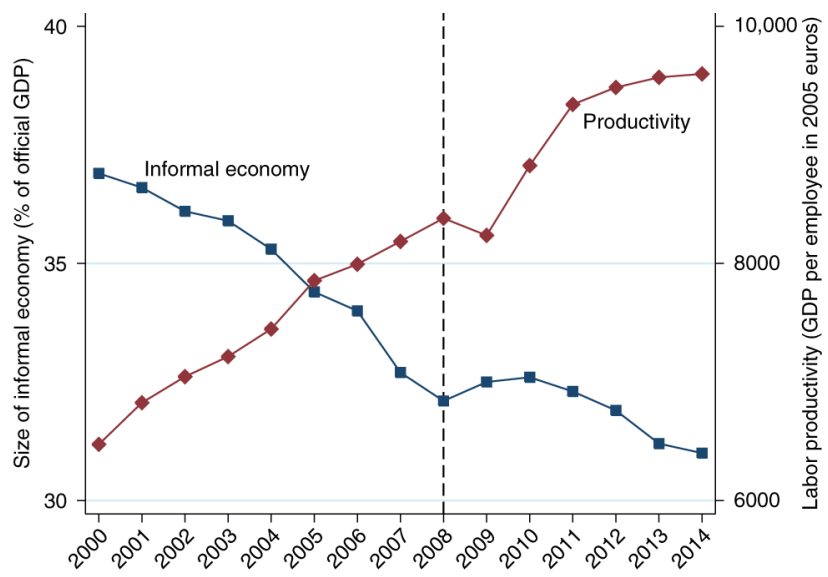

Figure 2: Size of informal economy and labor productivity.

Notes: The size of the informal economy is taken from Schneider and Enste (2013) and Schneider (2015). The average labor productivity is taken from the International Labor Organization Key Indicators of the Labour Market (ILO-KILM) 16a database.

Figure 3 depicts four indicators of the institutional efficiency and the quality of governance in Bulgaria in the last 15 years reported by the World Bank. The indicators for government effectiveness, regulatory quality, rule of law, and control of corruption range from -2.5 (weak governance) to 2.5 (strong governance). All four measures of institutional efficiency do not change significantly over the analyzed period. Therefore, institutions are unlikely to have a major role in accounting for the observed decline of informality. 


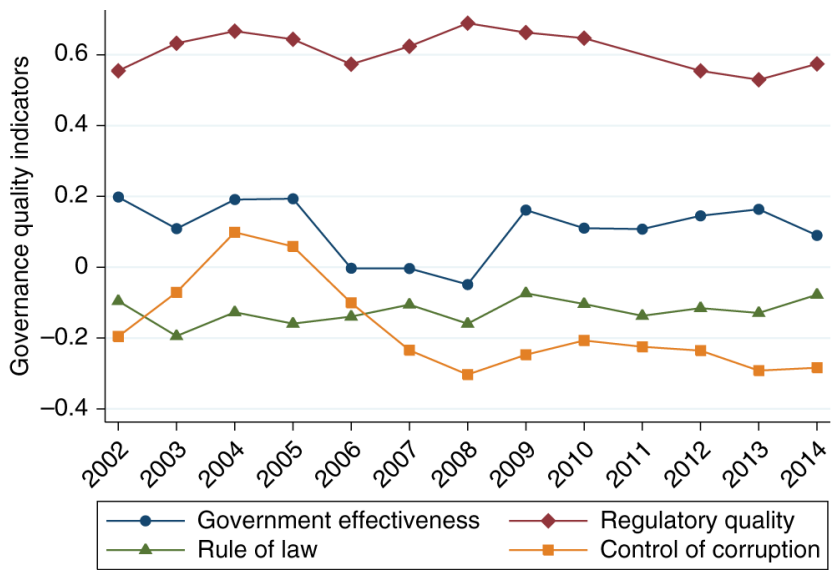

Figure 3: Governance quality.

Notes: The governance quality indicators are taken from the World Bank Worldwide Governance Indicators (WB-WGI) database. We include the data from 2002 on because of lack of availability for the previous years. See Online Appendix A.1 for additional details about these indicators.

\subsection{Taxes and social contributions}

Another factor that may have contributed to the decline in the informal economic activity, and therefore tax evasion in Bulgaria, is the changing tax system. Here we summarize the changes in personal and corporate income tax code and the social contribution levels over the years. ${ }^{9}$

The personal income tax schedule underwent a number of major reforms in the last 15 years. Figure $4 \mathrm{~A}$ depicts the average tax rate as a function of income. This tax schedule applies to the earnings of workers in the economy. Several observations are in order. First, the top marginal tax rate has decreased dramatically in the first part of the time period, from $40 \%$ in 2000 to $24 \%$ in 2007. This led to a decrease of the average rate for high earners. Second, in 2008 a flat tax of $10 \%$ was introduced without any deductible amount. ${ }^{10}$

To further clarify the changes in the income tax schedule we estimate the parameters of a popular tax function recently used by Benabou (2002), Guner, Kaygusuz, and Ventura (2014), and Heathcote, Storesletten, and Violante (2016) among others. The particular functional form we employ is given by $t(y)=1-\alpha y^{-\tau}$, where $y$ is taxable income relative to mean income and $t(y)$ is the average tax rate on it. The two parameters of the function summarize the level of the taxation at mean taxable income $(1-\alpha)$ and the level of tax progressivity $(\tau)$. The estimated $1-\alpha$ and $\tau$ for each year in the time period are displayed in Figure 4B. The average tax rate at mean income, $1-\alpha$, has a general decreasing trend over time but the magnitude of the change is fairly small. However, the level of progressivity $\tau$ drops significantly with the introduction of the flat tax in 2008 and then stays constant at zero for the rest of the period.

The rate of the proportional corporate income tax was at an all-time high in 2000 at $32.5 \%$. Several governments in a row implemented tax cuts by reducing this rate down to $15 \%$. Finally, in 2008 the corporate income tax was further slashed down to $10 \%$ (see Figure 4C). This came along with the corresponding reduction in the personal income tax to a flat rate of the same magnitude.

The last item to be discussed about the Bulgarian tax system is the social contributions paid by employers and employees. These contributions consist of payments for unemployment, disability, maternity, pensions and health insurance of the employees. However, they are levied on both the employer and the employee. The time evolution of social contribution rates of employers and employees is depicted in Figure 5. The employee's rate varies slightly during the years, but its general level is always around $12-13 \%$. The employer's contribution, however, fell sharply from more than 35\% in 2000 to less than $20 \%$ after 2008. 

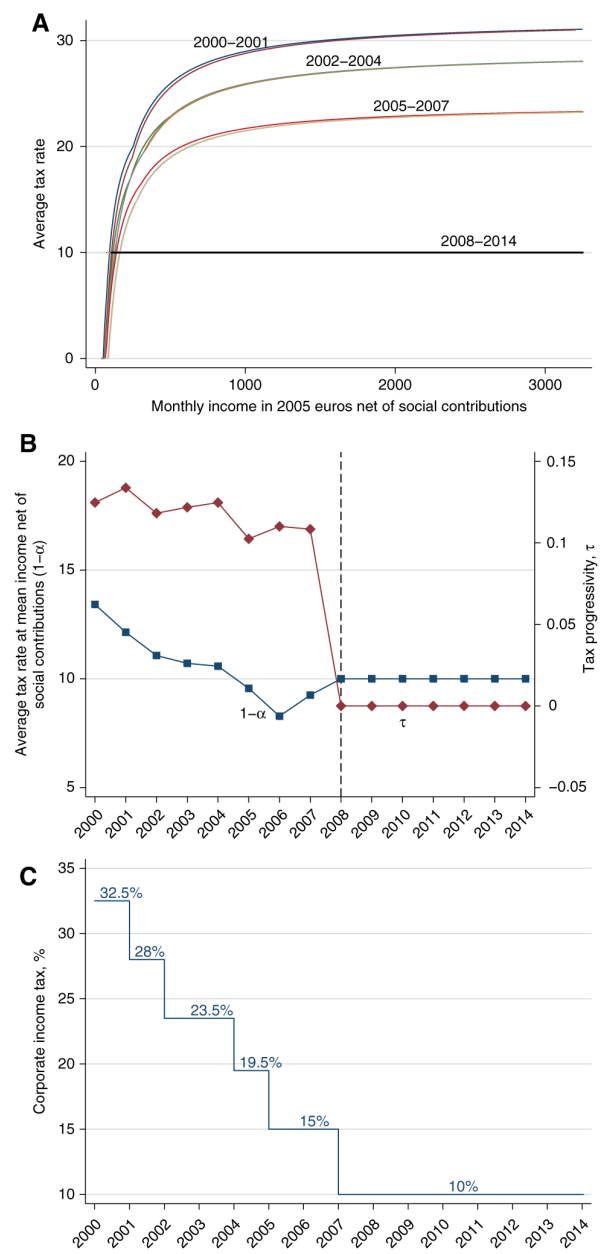

Figure 4: Personal income and corporate taxes.

(A) Average Personal Income Tax Rates (B) Estimated Tax Functions for Personal Income (C) Corporate Income Taxes Notes: Tax rates for Bulgaria in 2000-2014 are derived using accounting tax calculators; see Online Appendix A.2. For details on the estimation of the tax functions and the interpretation of the parameters, see Online Appendix A.3.

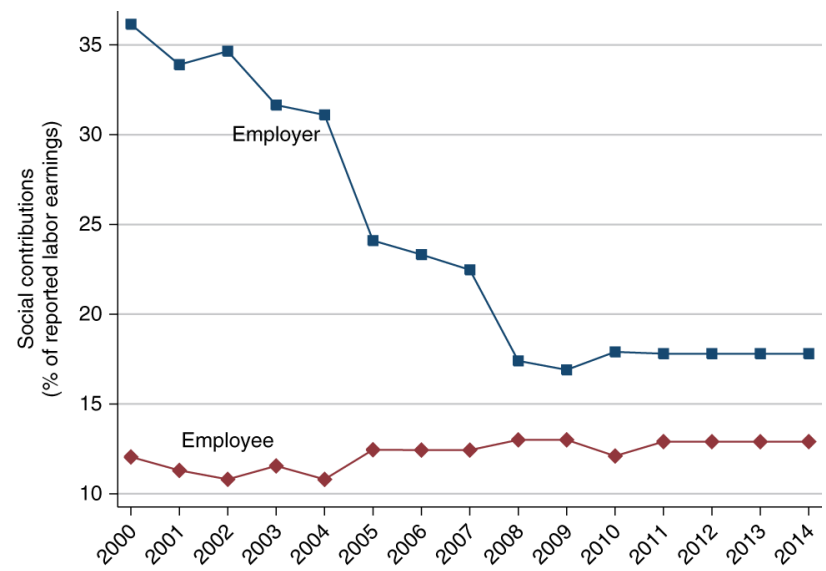

Figure 5: Social contribution rates paid by employers and employees.

Notes: Social contribution rates for Bulgaria in 2000-2014 are derived using accounting tax calculators; see Online Appendix A.2.

\subsection{Wages}

Figure 6 depicts the evolution of the minimum level of personal income (the legally binding minimum wage) for 2000-2014. For comparative proposes, we also plot the time series for average monthly wage income for the same period. The ratio of minimum income as a fraction of average income throughout the period oscillates in the interval 0.3-0.4. This ratio has similar values in other Eastern European countries but is much higher in 
Western Europe. ${ }^{11}$ Also, we note that a third of all employed Bulgarians receive minimum wages. This number comes for a written reply of the finance minister to the Bulgarian parliament. Based on expert calculations, the finance minister claims that 1,007,695 workers get minimum wages, while the overall number of employed people is 3,031,900 in $2015 .^{12}$

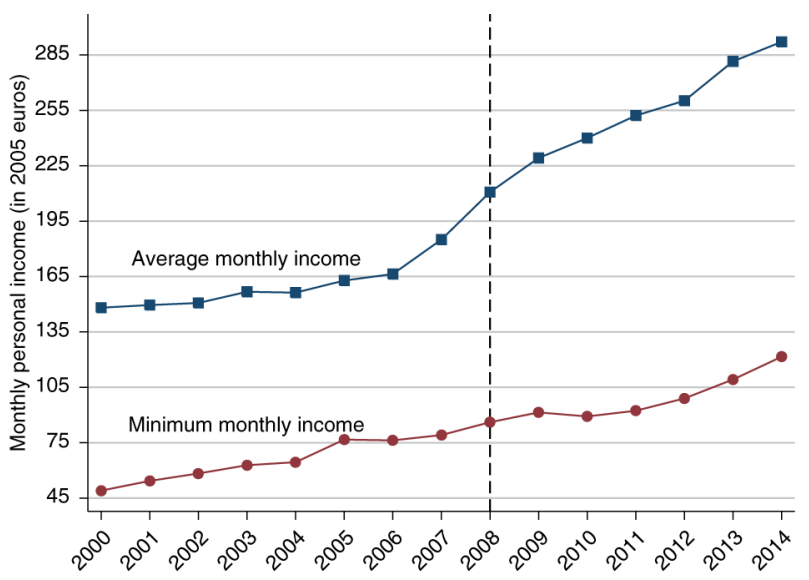

Figure 6: Average and minimum personal income.

Notes: Average and minimum income for Bulgaria in 2000-2014 are taken from the National Statistical Institute.

Observed average wages in Bulgaria for the period 2000-2014 are important data targets for the estimated model presented in the next sections. At the same time the evolution of minimum wages will be used as an input series in the model.

\section{The model}

In this section we develop an equilibrium model of informal production that incorporates the main ingredients needed to describe tax evasion practices in Bulgaria. Then, the model is estimated on observed time-series data and used for quantitative work and counterfactual experiments.

\subsection{Economic environment}

Time is discrete and each period the economy is re-populated by a large number of one-period lived employers with different productivity levels. Each period, an equal measure of homogeneous workers enters the economy. Workers are randomly distributed to employers forming potentially productive pairs which we will refer to from now on as islands. Once matched, workers cannot relocate to a different employer. ${ }^{13}$

Production on each island depends on the productivity of the employer, which is given by $\lambda$, and an aggregate productivity shock $z$, which hits the economy each period. In addition, workers can either supply a unit of labor in production or be inactive in which case production is not undertaken. Even though there might be potentially inactive workers on other islands, the employer cannot access them. This is the central frictional element in our environment. The outside options related to inactivity of both the worker and the employer are set to zero. ${ }^{14}$ The fact that the employer cannot call another worker if the current one refuses to cooperate, gives rise to a production surplus which can be shared between the two parties through bargaining.

The production when undertaken is given by the following production function,

$$
y=z \lambda
$$

The island-specific productivity $\lambda$ is distributed according to a distribution $F(\lambda)$ with support $[\underline{\lambda}, \infty)$. We normalize the mean of distribution $F$ to unity. Thus, if all islands are active in production, the average island productivity in the economy is unity and the aggregate production equals $z$. Employers and workers are riskneutral and their payoffs are given by the net remuneration from production, i.e. a wage for the worker and a profit for the employer net of personal/corporate income taxes and social contributions. The social contributions related to a job position are paid by both the employer and the worker via payroll taxes. In particular, if the job position is associated with an earnings level of $w$, then the employer needs to contribute $S_{E}(w)$, while 
the worker pays $S_{W}(w)$. These tax functions are given by $S_{E}(w)=\min \left\{s_{E} w, \bar{S}_{E}\right\}$ and $S_{W}(w)=\min \left\{S_{W} w, \bar{S}_{W}\right\}$. Essentially, the social contributions are proportional to the worker's earnings but cannot exceed the ceilings $\bar{S}_{E}$ and $\bar{S}_{W}$. This formulation follows closely the observed structure of payroll taxes in Bulgaria. Labor income net of payroll tax, $w-S_{W}(w)$, is subject to the personal income tax schedule $T_{W}(\cdot)$, which is increasing in the tax base, and allows for an arbitrary degree of progressivity. Business income $e$ net of social contributions $S_{E}(w)$ paid by the employer is taxed at a proportional rate $t_{E}$. Note that the payroll taxes $S_{E}(w)$ covered by the employer are deductible from business income $e$.

The productive pair on each island makes decisions on wages, profits and tax evasion. We assume that the production surplus is split according to a Nash-bargaining procedure. An important institutional detail that we introduce in the model is the presence of a minimum wage, $w_{\text {min }}$. The reported remuneration of a worker cannot fall below this threshold.

It is instructive to first describe the case in which the productive pairs are not allowed to evade any taxes. In this case, they bargain over the net payments they would receive from production, taking into account the taxes and social contributions levied by the government subject to the worker's outside option. Now think of the process of tax evasion. First, let us clarify that the tax authorities can observe the aggregate productivity level $z$ in the economy but do not have any information on the island-specific productivity levels $\lambda$. Therefore, they do not observe the overall productivity level on the island. This creates possibilities of tax evasion conducted jointly by the employer and the employee by underreporting their production. In doing so, the productive pair on an island needs to mimic the decision-making process in the case of no tax evasion.

Hiding production is costly. If the pair coordinates on hiding $h$, they incur an output loss of $x(h)$. The cost function $\mathcal{\kappa}(\cdot)$ is increasing and convex in the hidden amount. Then, the reported production is given by $\hat{y}=y-$ $\kappa(h)-h$. The forgone output due to tax evasion reflects the resources spent on concealing the informal economic activities from the fiscal authorities. ${ }^{15}$ Our model does not feature explicitly the Allingham and Sandmo (1972) setup where tax evaders face a probability of being detected and, if that happens, they are subject to a fine. Since agents are risk neutral in our model, the cost of evasion function can be interpreted as an expected punishment incurred when underreporting income. In this sense our cost function provides a parsimonious way to model tax enforcement and other factors (such as quality of tax administration) that affect informality.

The decision on tax evasion is made by the employer and employee who maximize the total surplus due to tax evasion by comparing the benefits of tax evasion in terms of forgone tax payments and its costs. In doing so, they take into account the prevailing tax structure in the economy. In a second stage, they bargain on how to split the hidden production taking into account their outside options which are given by the net remunerations they would receive in the case of no tax evasion. The amount of hidden income that each employee receives is dubbed the envelope wage. The remaining hidden amount goes to the employer as an envelope profit. Therefore, the outlined environment captures the prevailing practices of tax evasion in Eastern and Southern Europe.

In the rest of this section we state the decision problems in the cases of no evasion and tax evasion faced on each island.

\subsection{The case of no evasion}

The aggregate productivity in the economy is given by $z$, which is a common knowledge. ${ }^{16}$ Suppose that the employer and the worker on an island with productivity $\lambda$, and therefore productive capacity $y=z \lambda$, do not hide any amount of production. Therefore, the reported production for tax purposes is $\hat{y}=y$. The outside options for the worker and the employer are set to zero, as explained in the previous section. The employer offers a wage according to the problem defined below,

$$
\max _{e \geq 0, w \geq w_{\min }}\left\{\left[\left(1-t_{E}\right)\left(e-S_{E}(w)\right)\right]^{\gamma}\left[w-S_{W}(w)-T_{W}\left(w-S_{W}(w)\right)\right]^{1-\gamma}\right\}
$$

subject to

$$
e+w=y
$$

and

$$
\left(1-t_{E}\right)\left(e-S_{E}(w)\right) \geq 0
$$

$$
w-S_{W}(w)-T_{W}\left(w-S_{W}(w)\right) \geq 0 .
$$


The bargaining power of the employer is given by $\gamma \in(0,1)$. The surplus of the employer is given by the amount of earned business income $e$ net of payroll taxes and corporate income taxes. The worker's surplus equals the earnings $w$ net of payroll and personal income taxes. The bargained wage $w$ is bounded below by the minimum wage that is exogenously fixed by the government.

The solution of the above problem can be summarized by the functions which define the split of the total production,

$$
e=e^{*}(y)
$$

and

$$
w=w^{*}(y) .
$$

In essence, functions (5) and (6) map the level of production to the income of the employer and the worker.

We define the after-tax income levels for workers and employers in the case of no tax evasion as

$$
c_{E}^{*}(y)=\left(1-t_{E}\right)\left(e^{*}(y)-S_{E}\left(w^{*}(y)\right)\right)
$$

and

$$
c_{W}^{*}(y)=w^{*}(y)-S_{W}\left(w^{*}(y)\right)-T_{W}\left(w^{*}(y)-S_{W}\left(w^{*}(y)\right)\right) .
$$

Analytical Results. It is possible to solve the decision problem with no tax evasion (1) in closed form if we impose concrete parametric forms on the tax functions. In particular, social contributions are set to be proportional as in the data. They can be written as $S_{E}(w)=s_{E} w$ and $S_{W}(w)=s_{W} w{ }^{17}$ The personal income tax is given by the following functional form,

$$
T_{W}(y ; \alpha, \tau)=y-\alpha y^{1-\tau}
$$

therefore, after-tax income is given by

$$
y-T_{W}(y)=\alpha y^{1-\tau}
$$

and the average tax rate is $1-\alpha y^{-\tau}$. This is a very flexible functional form that encompasses the cases of proportional taxes (if $\tau=0$ ) and progressive taxes (if $\tau>0$ ).

When $T_{W}(\cdot)$ is specified as in (9), problem (1) is fully tractable. If the minimum wage constraint is not binding, the decision rules for wages and profits (5) and (6) are given by

$$
e^{*}(y)=\alpha_{e}\left(\gamma, \tau, s_{E}\right) y
$$

and

$$
w^{*}(y)=\alpha_{w}\left(\gamma, \tau, s_{E}\right) y,
$$

where the shares of income going to the employer and the worker are

$$
\alpha_{e}\left(s_{E}, \tau, \gamma\right)=1-\frac{(1-\gamma)(1-\tau)}{\left(1+s_{E}\right)(1-\tau(1-\gamma))}
$$

and

$$
\alpha_{w}\left(s_{E}, \tau, \gamma\right)=\frac{(1-\gamma)(1-\tau)}{\left(1+s_{E}\right)(1-\tau(1-\gamma))}
$$


However, if $y<\frac{w_{\min }}{\alpha_{w}}$, the minimum wage constraint binds, and the decision rules for profits and wages (5) and (6) are modified to

$$
e^{*}(y)=y-w_{\min }
$$

and

$$
w^{*}(y)=w_{\min } .
$$

Therefore, the general decision rules for profits and wages can be written as

$$
e^{*}(y)=\min \left\{\alpha_{e}\left(s_{E}, \tau, \gamma\right) y, y-w_{\min }\right\}
$$

and

$$
w^{*}(y)=\max \left\{\alpha_{w}\left(s_{E}, \tau, \gamma\right) y, w_{\min }\right\}
$$

The decision rules for pre-tax profits and wages (12) and (13) are shown in Figure $7 .{ }^{18}$
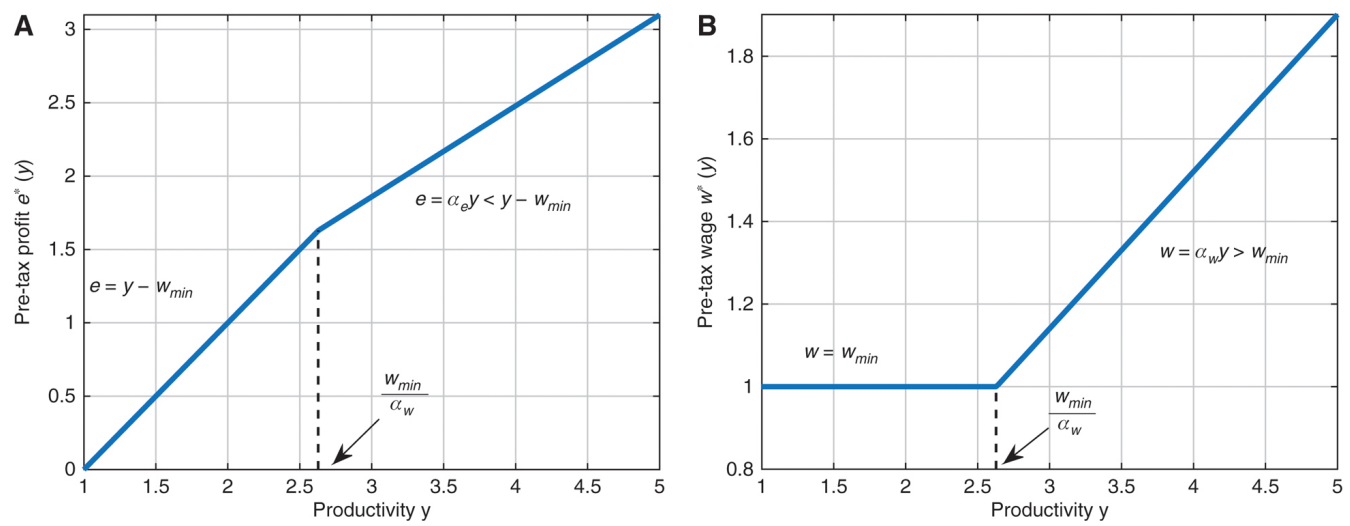

Figure 7: Profits and wages decision rules.

(A) Profits (B) Wages

What the effects of the different tax parameters on the splitting decisions for profits and wages? The following proposition addresses this. ${ }^{19}$

\section{Proposition 1}

The decision rules $e^{*}(y)$ and $w^{*}(y)$ have the following properties with respect to tax parameters:

i. $\frac{\partial e^{*}}{\partial \tau}>0$ and $\frac{\partial w^{*}}{\partial \tau}<0$,

ii. $\frac{\partial e^{*}}{\partial \alpha}=\frac{\partial w^{*}}{\partial \alpha}=0$,

iii. $\frac{\partial e^{*}}{\partial s_{E}}>0$ and $\frac{\partial w^{*}}{\partial s_{E}}<0$,

iv. $\frac{\partial e^{*}}{\partial s_{W}}=\frac{\partial w^{*}}{\partial s_{W}}=0$,

v. $\frac{\partial e^{*}}{\partial t_{E}}=\frac{\partial w^{*}}{\partial t_{E}}=0$.

Proof.

See Online Appendix A.4.

These comparative statics exercises show that whenever personal income tax progressivity is on the rise $(\tau \uparrow)$, pre-tax profits go up and earnings go down. This follows from the fact that with functional form (9), the after-tax income of the worker is given by $\alpha\left[\left(1-s_{W}\right) w\right]^{1-\tau}$. Therefore, upward changes in $\tau$ lead to a reduction of the marginal utility of wage $w$ to the worker. Naturally, the decision rules $e^{*}$ and $w^{*}$ reflect that. The other important tax rate for the determination of the income split is the rate of social contribution of employers, $s_{E}$. Whenever it increases, the payoff of the employer goes up to compensate him for the increased tax burden. At the same time, the payoff of the worker goes down. 


\subsection{The case of tax evasion}

Now suppose that the employer-employee pair on an island with productivity $\lambda$ can hide the level of production they conduct on their island, thus evading taxation. As explained above, the technology of tax evasion is associated with the cost $x(h)$ in terms of production, where $h$ is the total hidden income.

First, the employer and the worker need to decide on the reported level of island-specific productivity $\hat{\lambda}$ which implies that reported production is $\hat{y}=z \hat{\lambda}$. Second, they need to obey the publicly observed splitting rule stemming from problem (1), that is, the observed business and labor income should be given by

$$
(\hat{e}, \hat{w}) \in \arg \max _{e \geq 0, w \geq w_{\text {min }}}\left\{\left[\left(1-t_{E}\right)\left(e-S_{E}(w)\right)\right]^{\gamma}\left[w-S_{W}(w)-T_{W}\left(w-S_{W}(w)\right)\right]^{1-\gamma}\right\}
$$

subject to (2), (3) and (4). For instance, if the total agreed reported production is $\hat{y}$, then the reported employer's income $\hat{e}$ is consistent with the decision rule (5). The reported worker's income $\hat{w}$ must be in accord with decision rule (6). Thus, the reported wages and profits are consistent with reported production $\hat{y}$ and are set according to the functions

$$
\begin{gathered}
\hat{e}=e^{*}(\hat{y}), \\
\widehat{w}=w^{*}(\hat{y}) .
\end{gathered}
$$

Taking the resource constraint in the economy into account, the reported incomes of the employer and the worker sum up to the total reported production net of the cost of evasion,

$$
\hat{y}=y-h-\kappa(h)=e^{*}(\hat{y})+w^{*}(\hat{y}) .
$$

Therefore, choosing the total hidden amount is equivalent to choosing the reported level of production. Then, the bargaining problem amounts to making decisions about the levels of non-reported income by each party.

The decision process in the case of tax evasion is as follows. First, the employer and the worker determine the optimal amount of tax evasion that maximizes their joint earnings. The hidden amount $h$ is determined via the following optimization problem,

$$
\max _{h \geq 0}\left\{\hat{y}+h-t_{e}\left(\hat{e}-S_{E}(\widehat{w})\right)-S_{E}(\widehat{w})-S_{W}(\widehat{w})-T_{W}\left(\widehat{w}-S_{W}(\widehat{w})\right)\right\}
$$

subject to

$$
\begin{gathered}
\hat{y}=y-\kappa(h)-h, \\
\hat{y} \geq 0, \\
\hat{e}=e^{*}(\hat{y}), \\
\widehat{w}=w^{*}(\hat{y}) .
\end{gathered}
$$

Here the economic actors are mimicking other productivity types by adopting their policy rules from the nonevasion case. Only in such a way can they remain under the radar of the tax authorities and successfully hide output.

In a second stage, given the optimal amount of evasion $h^{*}(y)$ determined above, they decide how to split it by solving the following problem,

$$
\max _{h_{E}, h_{W}} h_{E}^{\gamma} h_{W}^{1-\gamma}
$$

subject to 


$$
h_{E}+h_{W}=h^{*}(y) .
$$

Essentially, they split the hidden amount in proportion to their bargaining power parameters. The solution to the bargaining problem is given by the decision rules on hidden incomes,

$$
h_{E}^{*}(y)=\gamma h^{*}(y),
$$

and

$$
h_{W}^{*}(y)=(1-\gamma) h^{*}(y) .
$$

Observe that the reported production can be expressed as

$$
\hat{y}=y-\kappa\left(h_{E}+h_{W}\right)-h_{E}-h_{W}=\hat{e}+\hat{w} .
$$

Then, combining (20), (21) and (22), we can redefine the reported income levels for the employer and the worker as functions of their production capacity $y$,

$$
\hat{e}=e^{* *}(y),
$$

and

$$
\widehat{w}=w^{* *}(y) .
$$

Analytical Results. Using the parametric assumptions on the tax functions from the case of no tax evasion, we can derive some analytical results here too. In addition, we assume that the cost function $\mathcal{k}(h)$ is differentiable, increasing and convex. Substituting the expression for reported production (17) and the mimicking constraints (18)-(19) into (16), we can express the objective function as

$$
y-\kappa(h)+\mathscr{A}\left(s_{E}, \tau, t_{E}, \gamma\right) \hat{y}+\mathscr{B}\left(s_{E}, s_{W}, \alpha, \tau, \gamma\right) \hat{y}^{1-\tau},
$$

where

$$
\mathscr{A}\left(s_{E}, \tau, t_{E}, \gamma\right)=-t_{E} \alpha_{e}\left(s_{E}, \tau, \gamma\right)-s_{E} \alpha_{w}\left(s_{E}, \tau, \gamma\right)\left(1-t_{E}\right)-\alpha_{w}\left(s_{E}, \tau, \gamma\right)<0
$$

and

$$
\mathscr{B}\left(s_{E}, s_{W}, \alpha, \tau, \gamma\right)=\alpha\left[\left(1-s_{W}\right) \alpha_{w}\left(s_{E}, \tau, \gamma\right)\right]^{1-\tau}>0 .
$$

The optimal level of hidden production is determined by the first-order condition related to expression (23),

$$
\mathcal{K}^{\prime}(h)=-\left[\mathscr{A}\left(s_{E}, \tau, t_{E}, \gamma\right)+\mathscr{B}\left(s_{E}, s_{W}, \alpha, \tau, \gamma\right)(1-\tau) \hat{y}^{-\tau}\right]\left[1+\kappa^{\prime}(h)\right] .
$$

The left-hand side of equation (24) represents the marginal cost of hiding income and we denote it from now on as $M C(h)$. This curve is always increasing in the hidden amount. This reflects the fact that if the employeremployee pair coordinate on a larger amount of evasion they have to spend more and more resources to keep their activities hidden from the fiscal authorities. The right-hand side is the marginal benefit of evasion which is denoted as $M B\left(h, y ; s_{E}, s_{W}, \alpha, \tau, t_{E}, \gamma\right)$ and it depends on all tax parameters. This curve is not necessarily increasing in the hidden amount as shown in the next paragraphs. Employers and workers maximize their joint earnings by equating the marginal cost of hiding income to the marginal benefit of doing so.

Equation (24) is portrayed in Figure 8A-Figure 8B. Figure 8A shows the case of the progressive income tax $(\tau>0)$ for a fixed island-specific productivity, whereas Figure $8 \mathrm{~B}$ depicts the case of a proportional tax $(\tau=0) .{ }^{20}$ In both cases the amount of tax evasion, $h$, is determined by the intersection of the curves for the marginal cost and benefit. When taxes are progressive, the marginal benefit curve has a positive slope for low levels of hidden income. However, for high levels of hiding, the slope of the curve becomes negative. For proportional taxes the curve is always increasing in $h$. 
A

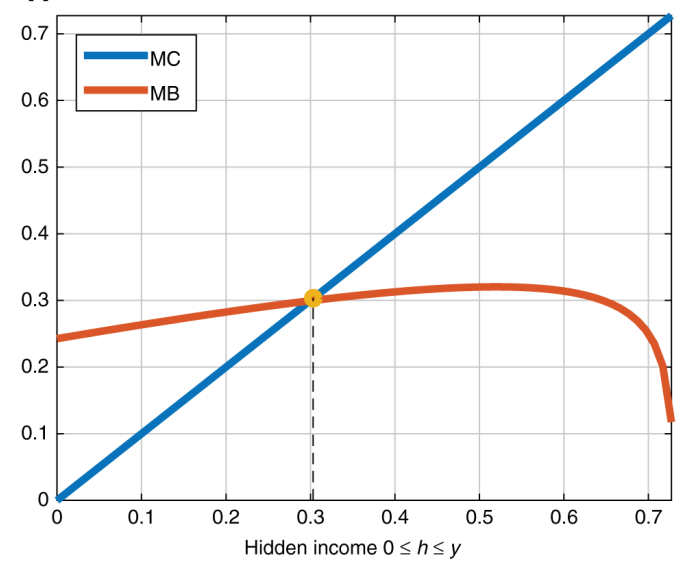

B

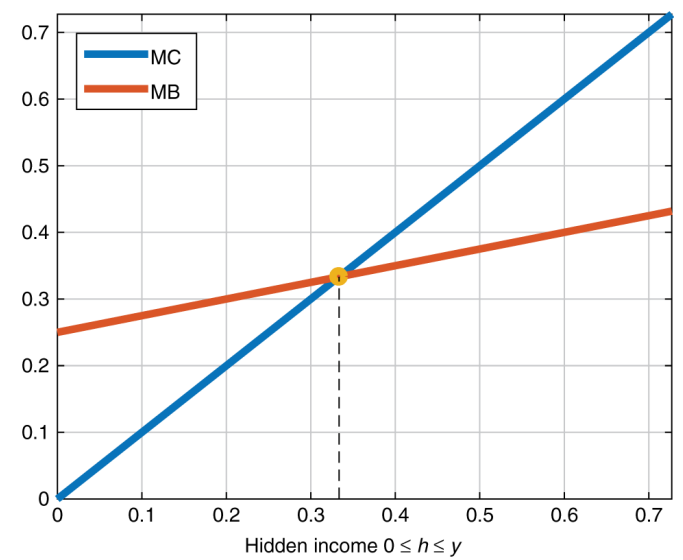

Figure 8: Marginal cost and benefit of evading taxes.

(A) Progressive Personal Income Tax, $\tau>0$ (B) Proportional Personal Income tax, $\tau=0$

A rise in any tax rate leads to a potential increase in the marginal gain from evading one more unit of production. In such a case hidden income $h$ increases. This is summarized in the following proposition:

\section{Proposition 2}

The decision rule for hidden income $h^{*}(y)$ has the following properties with respect to tax parameters,

i. $\frac{\partial h^{*}}{\partial \tau}>0$ if $y>\tilde{y}$, and the opposite is true if $y<\tilde{y}$

ii. $\frac{\partial h^{*}}{\partial \alpha}<0$,

iii. $\frac{\partial h^{*}}{\partial s_{E}}>0$,

iv. $\frac{\partial h^{*}}{\partial s_{W}}>0$,

V. $\frac{\partial h^{*}}{\partial t_{E}}>0$

\section{Proof.}

See Online Appendix A.4.

A rise in personal income tax progressivity $(\tau \uparrow)$ produces more tax evasion whenever the production capacity is sufficiently high (above the threshold $\tilde{y}$ ). If this is the case, an increase in progressivity leads to an increase in the marginal tax rate which in turn makes tax evasion more profitable. The other items in the proposition simply show the relationship between taxes and hidden income. ${ }^{21}$

Interestingly, the marginal benefit $M B$ depends positively on the level of productive efficiency $y$ as long as the personal income tax schedule is progressive, that is when $\tau>0$. The intuition here is as follows. Workers, who operate on more productive islands or face a rise in aggregate labor productivity $z$, earn higher reported wages as evident by the wage schedule (11). When taxes are progressive, they also face higher marginal tax rates compared to their less productive counterparts. Therefore, these workers have higher marginal benefit $M B$ of receiving envelope wages. However, if the personal income tax $T_{W}(\cdot)$ is proportional, the marginal tax rate does not depend on labor earnings but is constant and the optimality condition (24) is not affected by $y$,

$$
M C(h)=M B\left(h ; s_{E}, s_{W}, \alpha, t_{E}, \gamma\right)
$$

Let us perform the following thought experiment: suppose that productive capacity rises from $y$ to $y^{\prime}$, where $y^{\prime}>y$. How do the employer and the worker modify their tax evasion behavior? The $M C$ curve does not depend on $y$. The $M B$ depends on $y$ as long as $\tau>0$. If $\tau=0$, the optimal $h$ remains intact and the share of production that is concealed from the public authorities decreases mechanically. ${ }^{22}$ If instead $\tau>0$, an increase in $y$ will lead to an upward shift in the $M B$ schedule, hence $h$ increases as well. In this case, the effect on the fraction of production which is hidden, $h / \hat{y}$, is ambiguous. We can re-state the discussion above more formally in the following proposition: 


\section{Proposition 3}

An increase in productive efficiency (higher $y=z \lambda$ ) leads to higher concealed income $h$ if and only if the personal tax system is progressive (i.e. $\tau>0$ ),

$$
\left\{\begin{array}{l}
\frac{\partial h^{*}}{\partial y}=0 \Longleftrightarrow \tau=0 \\
\frac{\partial h^{*}}{\partial y}>0 \Longleftrightarrow \tau>0
\end{array} .\right.
$$

Proof.

See Online Appendix A.4.

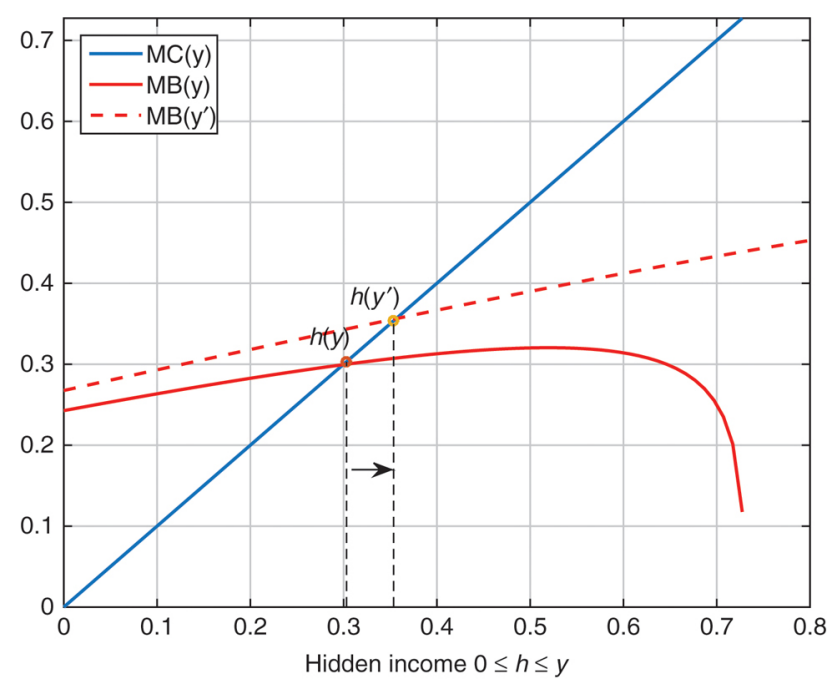

Figure 9: Comparative statics - an increase in productivity $\left(y^{\prime}>y\right)$.

A simple comparative statics exercise is depicted in Figure 9 to illustrate Proposition 3. When we increase productivity from $y$ to $y^{\prime}$, the marginal cost schedule is unaffected but the marginal benefit curve shifts upward when taxes are progressive. Thus, the optimal level of hidden income $h^{*}$ increases. The intuition here is that whenever marginal tax rates increase with income, tax evasion becomes more attractive.

\subsection{Aggregate statistics}

Here we report some important aggregate outcomes for the economy under investigation. These aggregates will be analyzed in detail in the next section where we describe the quantitative implementation of the model.

The total production capacity in the economy is given by the level of the aggregate productivity shock $z$ because $E(\lambda)=1 .^{23}$ That is,

$$
Y=z
$$

The amount of hidden production is given by

$$
H=\int\left[h_{E}^{*}(z \lambda)+h_{W}^{*}(z \lambda)\right] d F(\lambda) .
$$

The aggregate efficiency loss due to tax evasion is given by the costs of hiding in terms of forgone output,

$$
L=\int\left[\kappa\left(h_{E}^{*}(z \lambda)+h_{W}^{*}(z \lambda)\right)\right] d F(\lambda)
$$

Given the aggregate hidden amount and the aggregate efficiency loss, we can compute the reported production in the economy, i.e. the official GDP. ${ }^{24}$ It is

$$
\hat{Y}=Y-H-L
$$


We are interested in the size of the informal economy relative to reported production, which can be readily calculated as $H / \hat{Y}$, and in the share of production pairs which are constrained at the minimum wage,

$$
S=\int \mathbf{1}_{w^{* *}(z \lambda)=w_{\min }} d F(\lambda) .
$$

Finally, the tax revenue raised by the government is given by

$$
T=\int\left[T_{E}\left(e^{* *}(z \lambda)-S_{E}\left(w^{* *}(z \lambda)\right)\right)+T_{W}\left(w^{* *}(z \lambda)-S_{W}\left(w^{* *}(z \lambda)\right)\right)\right] d F(\lambda) .
$$

Note that expression (29) describes a generalized Laffer curve for this economy.

\section{Bringing the model to the data}

The model admits no closed form solution when tax evasion is permitted, hence we solve and simulate it with the help of numerical techniques. The model period is set to one year and the simulation is performed for the time period 2000-2014. We use the schedules for taxes and social contributions over the time period and the time series for the minimum wages as exogenous inputs to the model. Then, we use the environment to generate time paths for several aggregate statistics such as the overall size of the informal economy, the observed average monthly wages, the observed labor productivity (measured as output per worker), the average Gini coefficient of the observed after-tax labor income and the share of workers receiving minimum wage for the period 20002014. As argued later in the text, these moments are useful targets for estimating the model parameters. We match the model outcomes to the corresponding data moments using a minimum distance estimation strategy. Finally, we employ our quantitative environment to gauge the determinants of the informal economy and its changes over time through a series of counterfactual experiments.

Before proceeding to the details of the estimation procedure and the obtained model fit, let us briefly discuss how the tax system is introduced to the model and what parametric assumptions are made.

Taxes and Social Contributions. We directly use the observed tax schedules for the personal income tax, $T_{W}(\cdot)$, the corporate business tax, $T_{E}(\cdot)$, the social contributions of the employer, $S_{E}(\cdot)$, and the social contributions of the employee, $S_{W}(\cdot){ }^{25}$

Functional Forms. We choose a general functional form for the cost of evasion, with two parameters,

$$
\kappa(h)=\beta \exp (\theta h) .
$$

The parameter $\beta$ governs the level of the cost of hiding, while $\theta$ controls its curvature. The island-specific productivity $\lambda$ is assumed to follow a log-normal distribution with mean $-\sigma^{2} / 2$ and variance $\sigma^{2}$. This implies that the mean of the of $\lambda$ is unity. ${ }^{26}$

\subsection{Estimation}

We consider the two parameters related to the cost of hiding, $\beta$ and $\theta$, the bargaining parameter $\gamma$ (more precisely, the employer's bargaining power), the variance $\sigma^{2}$ of the island-specific productivity $\lambda$, and the sequence of unobserved labor productivity level, $\left\{z_{t}\right\}_{t=2000}^{2014}$ for the time period 2000-2014. We estimate these 19 parameters by matching 47 data moments; see Online Appendix A.1 for details. The data targets that we consider are:

1. The size of the informal economy (2000-2014) [15 targets]

2. Observed average monthly wages (2000-2014) [15 targets]

3. Observed labor productivity measured as output per worker (2000-2014) [15 targets]

4. Gini coefficient of disposable labor income and share of workers receiving minimum wage (2000-2014 average) [2 targets]. 
A discussion of the parameter identification strategy is in order. It is well understood that changes to any of the parameters considered in estimation affect the model outcomes for all of the above moments. However, some moments are more responsive to certain parameters. Heuristically, a moment target is informative about an unknown parameter if that target is sensitive to changes in the parameter value.

In order to pin down the values of the parameters related to the cost of hiding ( $\beta$ and $\theta$ ), we match the 2000-2014 time series of the size of the informal economy. The mean of the size of the informal economy across time is informative about the level of the cost of evasion, captured by the parameter $\beta$. A higher value of $\beta$ shifts down the size of the informal economy in all years. The curvature of the cost function $(\theta)$ affects the changes in the size of the informal economy. Therefore, $\theta$ is recovered by matching the decreasing pattern of tax evasion over time.

One advantage of our estimation strategy is that we can identify the parameters of the cost function of hiding income without using data on the cross-section of tax evasion (which is not available). For the time being, think of all other parameters of the model as fixed. Then, the hidden amount of production on an island in the model can be represented as a function of the island-specific productivity $\lambda$ and the cost parameters $(\beta, \theta)$. We omit all other parameters that do not change over time. Therefore, denote this function as $\tilde{h}(\lambda, \beta, \theta, z)$. The corresponding cost of hiding is a function of the hidden amount and the parameters $(\beta, \theta)$, so we can also express it as a function of the island-specific productivity and the parameters $(\beta, \theta)$; call it $\tilde{\kappa}(\lambda, \beta, \theta, z)$. Then, the values of the two parameters $(\beta, \theta)$ need to be set to match a sequence of 15 targets for the size of the informal economy. Algebraically, the parameter estimates for $(\beta, \theta)$ are the ones that minimize the squared distance between the data and the model moments below,

$$
\begin{aligned}
& d_{H / \hat{Y}}^{2000}=\frac{\int \tilde{h}(\lambda, \beta, \theta) d F(\lambda)}{z_{2000}-\int \tilde{h}(\lambda, \beta, \theta) d F(\lambda)-\int \tilde{\kappa}(\lambda, \beta, \theta) d F(\lambda)}
\end{aligned}
$$

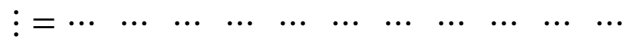

$$
\begin{aligned}
& \begin{array}{lllllllllllll}
\vdots & = & \cdots & \ldots & \ldots & \ldots & \ldots & \ldots & \ldots & \ldots & \ldots & \ldots & \ldots
\end{array} \\
& \begin{array}{lllllllllllll}
: & = & \ldots & \ldots & \ldots & \ldots & \ldots & \ldots & \ldots & \ldots & \ldots & \ldots & \ldots
\end{array} \\
& d_{H / \tilde{Y}}^{2014}=\frac{\int \tilde{h}(\lambda, \beta, \theta) d F(\lambda)}{z_{2014}-\int \tilde{h}(\lambda, \beta, \theta) d F(\lambda)-\int \tilde{\kappa}(\lambda, \beta, \theta) d F(\lambda)},
\end{aligned}
$$

where the left-hand side variable in the individual equations denotes the observed size of the informal economy over time in the data, $\left\{d_{H / \hat{Y}, t}\right\}_{t=2000}^{2014}$. The right-hand side of each equation expresses the size of the informal economy implied by the model as a function of the cost parameters $(\beta, \theta)$. Clearly, the system of equations is over-identified given that there is sufficient variation over time of the size of the informal economy and the true productivity. In other words, our identification strategy for the parameters of the cost function of tax evasion rely on the time-series variation of the size of the informal economy and the observed labor productivity.

The level of observed wages for 2000-2014 is used to identify the bargaining parameter $\gamma$. Workers remuneration consists of observed wages and unobserved envelope wages. By matching the overall size of the informal economy, we essentially determine the sum of hidden income for workers and employers. Then, the bargaining parameter $\gamma$ determines the split of this hidden income between workers and employers. It also determines the levels of observed wages and profits.

The wage inequality observed in the data helps us to identify the variance of the island-specific productivity process, $\sigma^{2}$. In this case, we match the 2000-2014 average of the Gini coefficient of labor income since our model cannot capture by construction many features that affected inequality in the data (globalization, skillbiased technological change and trade shocks among others). In addition, we match the share of workers with minimum wage. This moment is also strongly influenced by the variance of the island-specific productivity process. Finally, our last target is the evolution of the observed labor productivity between 2000 and 2014. This set of moments is informative about the true production capacity of the economy, before the resource cost of tax evasion and the hidden income are taken into account. This is interesting because we use the model to estimate a moment (true labor productivity) that cannot be observed in the data.

The parameters to be estimated are summarized in the following vector,

$$
\Theta=\left\{\beta, \theta, \gamma, \sigma^{2},\left\{z_{t}\right\}_{t=2000}^{2014}\right\} .
$$

Let $d$ represent the vector of 47 data targets. The vector $\hat{m}(\Theta)$ contains the analogous model moments which are a function of the parameter vector $\Theta$. We define the difference between the data targets and the corresponding model moments as 


$$
g_{i}(\Theta)=d_{i}-\hat{m}_{i}(\Theta),
$$

for $i=1, \ldots, 47$.

The minimum distance procedure chooses the optimal parameters in order to bring the model as close as possible to the data. More precisely, it picks $\Theta$ to minimize the weighted sum of squared deviations between the data and the model,

$$
\hat{\Theta}=\min _{\Theta} g(\Theta)^{\prime} \mathscr{W} g(\Theta)
$$

where $W$ is a positive semidefinite matrix. The estimator $\hat{\Theta}$ is consistent for any positive semidefinite weighting matrix (Lee and Ingram 1991). We choose the identity matrix, i.e. $W=I$.

\subsection{Estimation results}

The parameter estimates are summarized in Table 1. The estimated parameters related to the cost of evasion, $\beta$ and $\theta$, do not have an immediate economic interpretation. The estimated cost function implies very small penalty for small hidden amounts. However, it implies much higher levels of penalty for realistic levels of evasion and it is highly convex. It is interesting to focus on the estimate for the employer's bargaining power, $\gamma$. Our bargaining model obtains a good match to the data of observed wages whenever $\gamma$ takes values close to 1 . Such a value implies that the employer is able to get most of the income generated by production. This result suggests that taxes affecting the employer's profits are going to play a major role in determining the decision to hide income. Taxes levied on the income of workers, on the contrary, would not matter so much for tax evasion because wages are only a small fraction of total production.

\begin{tabular}{|c|c|c|}
\hline Parameter & Description & Value \\
\hline$\beta$ & Cost of evasion - level & $0.20255 \cdot 10^{-7}$ \\
\hline$\theta$ & Cost of evasion - curvature & 0.00725 \\
\hline$\gamma$ & Employer bargaining power & 0.97410 \\
\hline$\sigma^{2}$ & Variance of productivity & 0.50066 \\
\hline$\left\{z_{t}\right\}_{t=2000}^{2014}$ & Output per worker & see Figure 11B \\
\hline
\end{tabular}

Table 1: Parameter estimates.

The variance of productivity distribution, $\sigma^{2}$ is estimated to be around 0.5 , while the aggregate labor productivity is estimated to vary between 10,390 and 12,389 euros across years. The differences between the estimated (true) and observed labor productivity levels will be discussed in the next subsection.

\subsection{Model fit}

The model does a very good job in matching the declining trend of the size of the informal economy over time in Bulgaria; see Figure 10A. It slightly overemphasizes the importance of the shadow economy at the beginning of the sample and slightly underpredicts it for the last two years, but these differences between the model and the data are fairly small. Figure 10B and Figure 10C present the the model fit in terms of average observed wages and observed labor productivity over time. Here again the model performs well in terms of matching the trends in the data. 

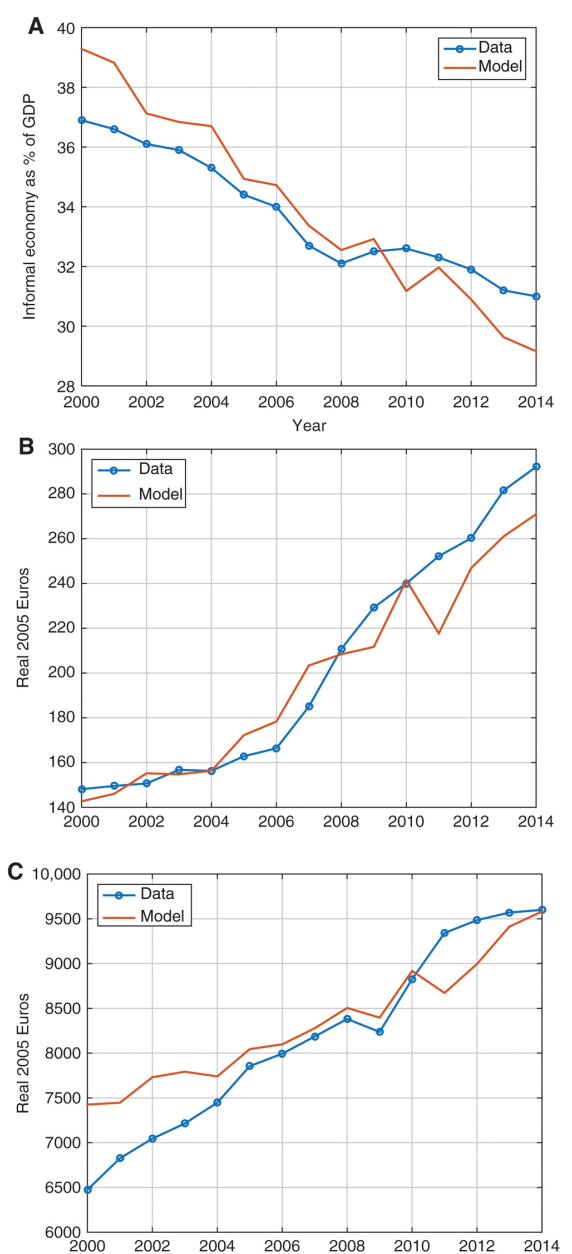

Figure 10: Model fit - time trends.

(A) Size of Informal Economy (B) Observed Wages (C) Observed Labor Productivity

To better assess the model goodness of fit, we compute the time-average of the data targets presented on Figure 10 and compare them with their model counterparts. Table 2 shows these comparisons. It also features the additional two average data targets for the period 2000-2014, namely the Gini coefficient of disposable income and the share of workers paid the minimum wage. The model has no problem matching most of the aggregate targets. However, it overpredicts income inequality measured by the Gini coefficient and underpredicts the share of workers receiving the minimum wage. Note that a reduction in the variance $\sigma^{2}$ of the island-specific productivity will lead to lower levels of observed wage inequality in the model. However, this reduction would also shrink the share of workers receiving the minimum wage. Thus, the estimation procedure finds a satisfactory fit for both of these aggregate targets which respond with different magnitude to changes in the parameter $\sigma^{2}$.

We conclude the discussion of the model fit by presenting two interesting predictions generated by the model which are not observed in the data. First, the model generates a cross-sectional distributions of tax evasion by the island-specific productivity. While we do not have micro data at the individual/establishment level to corroborate such predictions, we do find useful to discuss them in light of some additional evidence. Figure 11A plots the share of income hidden from the government as a function of production capacity on islands in ascending order in terms of their productivity. At the bottom of the productivity distribution, employers and workers decide to hide a large fraction of their output, while the fraction of evaded output is negligible at the top of the productivity distribution. More productive firms do evade taxes, however, they cannot afford to hide a more significant fraction of their potential output because of the increasing cost. If we assume that firm size and productivity are positively correlated, this finding is consistent with the existing evidence on firm size and informality. The World Bank Enterprise Survey 2013 finds that small and medium-size enterprises are more likely to face competition form the informal economy. The Eurobarometer survey also confirms that employees from small and medium-size companies are more likely to receive part of their remuneration as envelope wages. For more details, see Online Appendix A.1. As an additional step to further validate the negative relationship between productivity and informality delivered by our model, we perform a sectoral level analysis for Bulgaria. The data confirm that sectors with lower labor productivity have higher levels of informality. We refer the reader to Section 6 for an extensive discussion of this additional empirical analysis. 
A

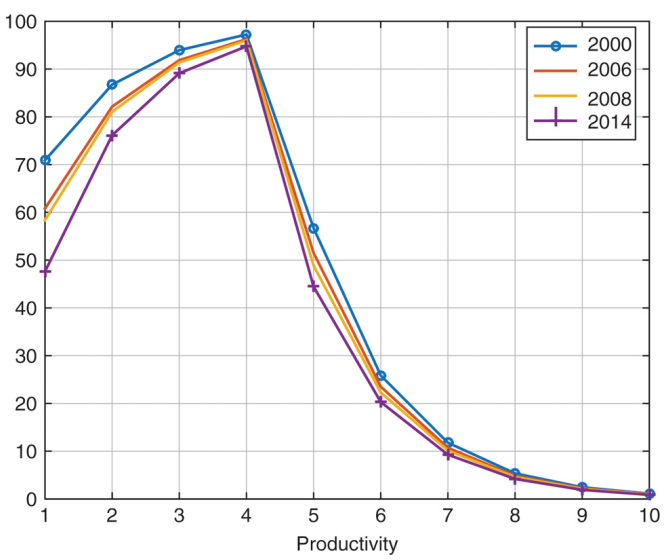

B

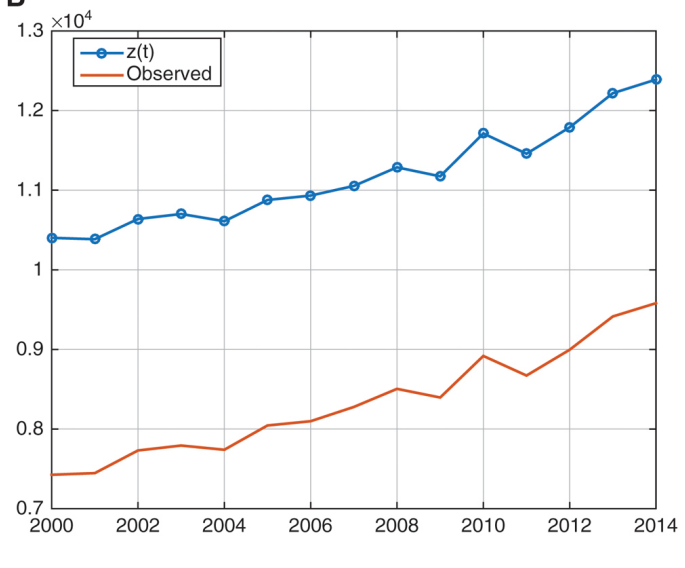

Figure 11: Model-generated facts.

(A) Hidden Output as a Share of Productive Capacity (\%), (B) Observed versus Unobserved Aggregate Productivity

Table 2: Model fit - time-averaged statistics.

\begin{tabular}{lrr}
\hline Averages (2000-2014) & Data & Model \\
\hline Informal economy (\% of GDP) & 33.7 & 34.0 \\
Observed wages & 203 & 198 \\
Observed labor productivity & 8165 & 8335 \\
Gini disposable income & 0.325 & 0.395 \\
Workers at min wage (\%) & 33.0 & 25.6 \\
\hline
\end{tabular}

Second, the estimated model allow us to retrieve the unobserved aggregate labor productivity across time. We compare the unobserved versus the observed labor productivity in Figure 11B. Both series increase over time (with the exception of the 2008-2009 period). The true production capacity averages around 12,000 euros whereas the observed one averages around 8,800 euros. Therefore, tax evasion implies that observed labor productivity is roughly $25 \%$ lower than its true value.

\section{Counterfactual experiments: productivity versus taxes}

Now we can use the estimated model economy for counterfactual analysis. We perform a set of quantitative experiments in order to quantify the relative effects of taxes and labor productivity on the size of the informal economy.

Shutting down Productivity Growth. In the first exercise, we keep labor productivity constant at its 2000 value over the whole time period 2000-2014. However, we feed in the model the correct tax schedules and their changes over time. Figure 12A plots the evolution of the informal economy in the baseline model and in this new counterfactual world. Therefore, we can assess how taxes alone matter for the observed decrease in informality (solid circle line). The distance between the two lines is due to the productivity growth over the period. Several things are worth mentioning. First, in the baseline scenario informality drops by around 10 percentage points (from $39 \%$ to $29 \%$ of GDP), whereas it decreases by only 3.55 percentage points when only taxes are at play. Hence, changes in taxation can account for less than a half of the change in the size of the informal economy. Second, almost all of the decline in informality induced by taxes takes place in the first half of the time period, between 2000 and 2007. This is not surprising, since the major tax reforms regarding employers were implemented before 2008, as we documented in Section 2. The fact that taxes did not have a sizable impact on informality after 2008 points out that the role of the 2008 personal income flat tax reform as a coping device against evasion was rather small.

Shutting down Tax Reforms. In the second counterfactual exercise, we keep all tax schedules at their 2000 levels. Essentially, we let productivity growth be the only driving force behind changes in informality. Tax reforms would not play any role because they are omitted (see Figure 12B). The rise of labor productivity over the period can account alone for a sizable fraction of the decline in informality. The informal size now declines from $39 \%$ to around $32 \%$ of GDP - a decrease of 7.68 percentage points; see Table 3 . 

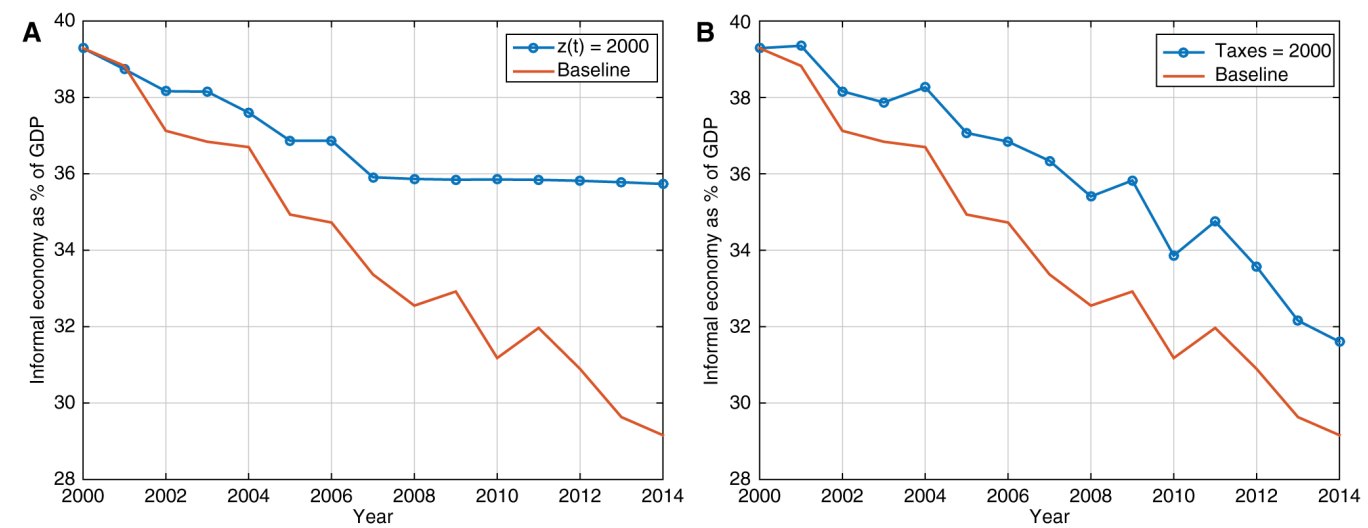

Figure 12: Productivity versus taxes.

(A) Shutting down Productivity Growth (B) Shutting down Tax Reforms

Table 3: Productivity versus taxes - a decomposition.

\begin{tabular}{lccc}
\hline & $\mathbf{2 0 0 0}$ & $\mathbf{2 0 1 4}$ & Change \\
\hline Model & 39.29 & 29.16 & $\mathbf{- 1 0 . 1 3}$ \\
Shutting down productivity & 39.29 & 35.74 & -3.55 \\
Shutting down tax reforms & 39.29 & 31.61 & -7.68 \\
\hline
\end{tabular}

Digging Deeper - The Role of Different Tax Reforms. So far we have documented that tax reforms alone account for more than a third of the decline in informality in the model (3.55 percentage points out of the total decline of 10.13 percentage points). How do changes in each of the three tax schedules in the model contribute to this result? We now turn our attention to decomposing the overall role of taxes into individual effects of the personal income tax, the corporate business tax, or the social security contributions.

To quantify the effect of personal income taxes more precisely, we solve the model by feeding in only the changes of the personal income tax code, while keeping all other taxes and productivity fixed at their 2000 levels. Figure 13A compares this counterfactual to the scenario in which all taxes change with a fixed productivity as in Figure 12A. It is clear that changes in personal income taxes did not play any relevant role for the decline of the size of the informal economy. Neither the flat tax reform in 2008, nor the previous reductions in the effective marginal tax rates had a sizable impact on tax evasion. All in all, personal income taxes account for only 0.27 percentage point decline in informal economy size (from 39.29\% to $39.02 \%$ ).

We perform a similar exercise with respect to the corporate income tax. Again keep productivity constant at its 2000 levels but allow only this tax to change over time. Figure 13B presents the comparison to the economy in which all taxes are allowed to vary. The results show that changing corporate income taxes account for all of the effect of taxes on informality (from $39.29 \%$ to $35.74 \%$ ).

Due to the high bargaining power of employers in the model, most of the value added from production accrues as profits. Therefore, taxes on profits are the most relevant factor influencing the marginal incentive to hide production. ${ }^{27}$ What about social contributions? Since wages are only a small fraction of total income from production, social contributions levied either on the employer or on the worker do not change significantly the incentives to report income. The relevant experiment is depicted on Figure 13C.

To sum up, the experiments point out that the most important driver for the decline of the informal economy in Bulgaria is the rise in labor productivity. It alone accounts for around three quarters of the observed decline in our model economy. Taxes play a secondary but not negligible role. Most of this effect comes from changes to the corporate income tax. 

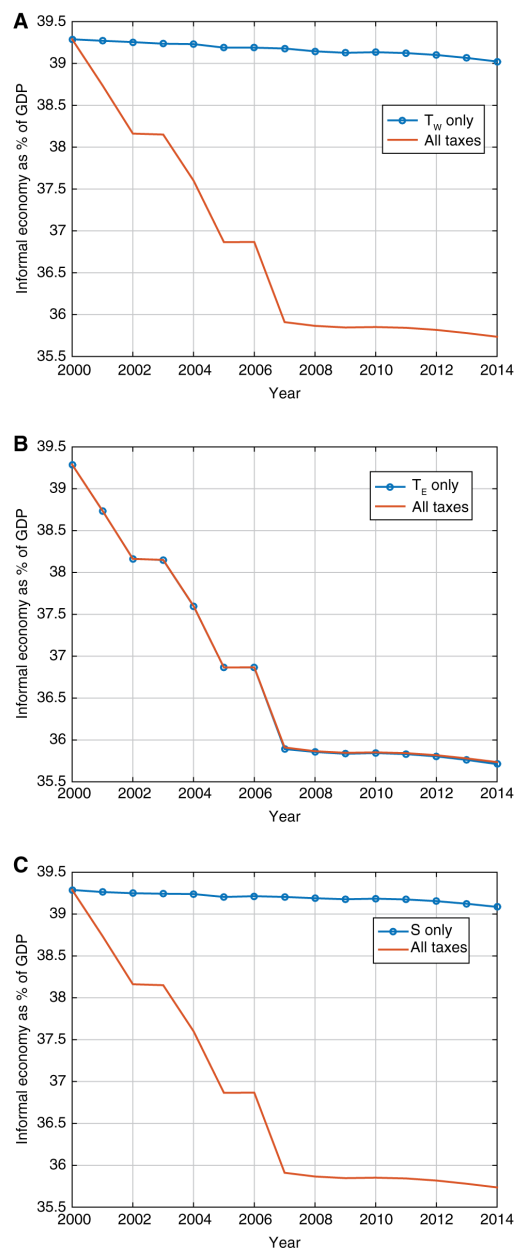

Figure 13: Digging deeper - the role of different tax reforms.

(A) Personal Income Tax (B) Corporate Income Tax (C) Social Contributions

\subsection{A path to a cross-country analysis}

Our model framework can be easily extended to other countries where informality happens within formally registered enterprises which offer formal wage contracts to workers and where wages and profits are partially hidden. As we argue in Section 1, this is the relevant case in Europe. More generally, our model contains three features that can be utilized in a potential cross-country comparison of the determinants of informality. First, countries can differ explicitly in the cost of tax evasion. ${ }^{28}$ Second, the bargaining power of workers can be different. Finally, minimum wages can differ across countries.

Here we provide an illustration of how the bargaining power of workers, which can vary across countries depending on the specific labor market institutions, affects the importance of taxes for generating informality. In the baseline economy estimated to Bulgaria tax reforms influence the informal economy size mostly through the decline of corporate taxes. This result is related to the high estimated value of the bargaining strength of employers $(\gamma=0.974)$.

To capture the labor market institutions in countries where workers have more power, we lower gradually the value of $\gamma$ from the estimated value of 0.97 down to $0.5 .^{29}$ This significantly reduces the impact of corporate taxes on informality. As mentioned before, in the baseline economy $(\gamma=0.974)$ changes in taxes account for a decline of informality of 3.55 percentage points. Personal income taxes account for only $8 \%$ of the decline as shown on Figure 13A. We perform similar decomposition exercises when the bargaining power of the employers takes lower values. When $\gamma=0.8$, changes in personal income taxes become more important and account for $19 \%$ of the overall decline of informality attributed to taxes. Corporate taxes still account for $79 \%$ of the overall decline due to taxes (see Figure 14A). Finally, when $\gamma=0.5$, the contribution of the personal income taxes becomes quantitatively similar to the contribution of the corporate business taxes. Both of these tax changes account for approximately $45 \%$ of the overall decline in the informal economy size due to taxes. Figure $14 \mathrm{~B}$ present the time path for informality in this set of counterfactual experiments. Our findings suggest that the effect of personal 
income tax and/or employees' social contributions on informality is likely to be stronger in countries where workers have more bargaining power.
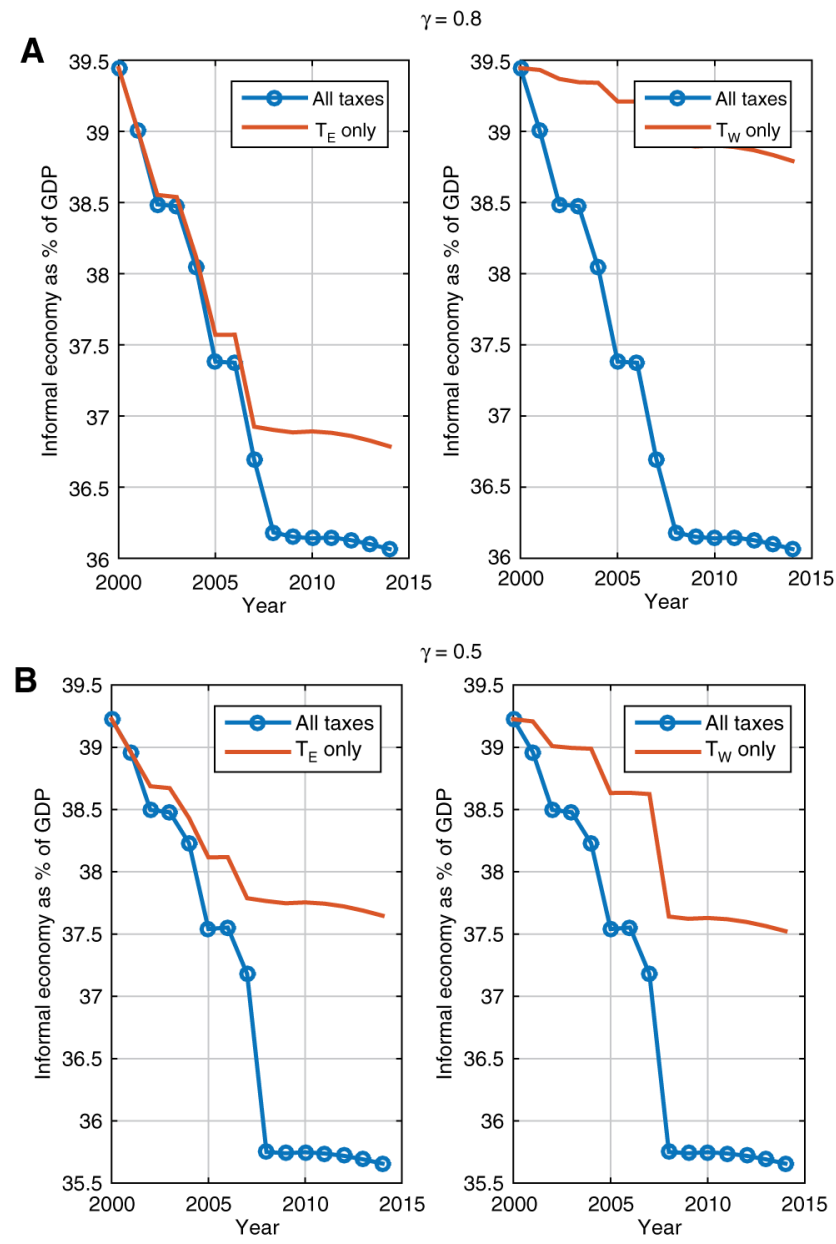

Figure 14: Power to the workers - sensitivity analysis.

(A) $\gamma=0.8$ (B) $\gamma=0.5$

\section{Validating the mechanism}

We re-evaluate the results of our quantitative analysis in the light of additional empirical evidence. To be more precise, we now test some of the implications of our quantitative analysis using data on informality, taxes and labor productivity across countries and across sectors (in the case of Bulgaria). If the economic mechanism described in the previous section is relevant and can be generalized across time and levels of aggregation, one should observe that

a) across countries and over time: Countries with higher labor productivity have a lower level of tax evasion/informality ceteris paribus. In addition, countries which experience stronger productivity growth also have a sharper decrease in informal production.

b) across firms and/or sectors: Smaller and less productive firms are more likely to tax evade and pay envelope wages than large firms. ${ }^{30}$ Due to lack of firm-level data, we test a similar hypothesis at sectoral level using data on agriculture, manufacturing and services in Bulgaria. Our quantitative analysis implies that sectors with lower labor productivity have higher levels of informality and tax evasion.

Validation across Countries. The analysis performed here relies on a panel dataset consisting of 30 countries for the time period 1999-2013. The measured variables of interest are the size of the informal economy and the prevailing labor productivity measured by output per hour worked. ${ }^{31}$ Figure 15 depicts the empirical relation between labor productivity and informality with no additional controls across the countries in our sample. The correlation between the two variables is strongly negative $(-0.64)$, which provides a first confirmation of the role of productivity we have documented in the model. Furthermore, the mechanism is confirmed in a set of estimated regression specifications in Table 4. The correlation between the two variables of interest is significantly negative even when we control for time effects. Moreover, specifications (3)-(4) add country fixed 
effects which allows us to focus on the association between labor productivity and informality within countries over time. The magnitude of the correlation is smaller but still highly significant and negative.

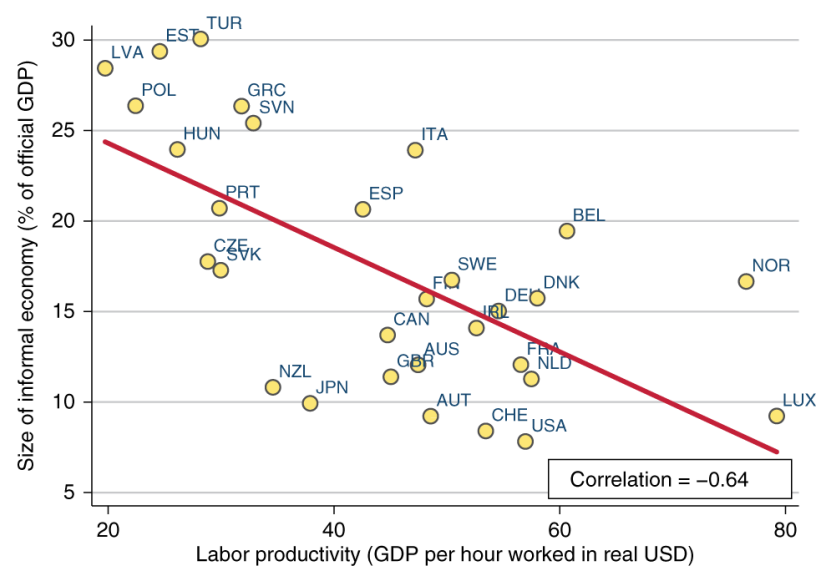

Figure 15: Informality and labor productivity across countries, 1999-2013 averages.

Notes: The size of the informal economy is taken from Schneider and Enste (2013). Labor productivity is measured by GDP per hour worked in 2010 USD and comes from the ILO-KILM 16a database.

Table 4: Informality and labor productivity across countries and over time, 1999-2013.

\begin{tabular}{lllll}
\hline & \multicolumn{4}{l}{ Dependent variable: Informality } \\
\cline { 2 - 5 } & $\mathbf{( 1 )}$ & $\mathbf{( 2 )}$ & $\mathbf{( 3 )}$ & $\mathbf{( 4 )}$ \\
\hline Output per hour worked & $-0.719^{* * *}$ & $-0.703^{* * *}$ & $-0.670^{* * *}$ & $-0.224^{* * *}$ \\
Country fixed effects & $(0.124)$ & $(0.127)$ & $(0.119)$ & $(0.0627)$ \\
Time fixed effects & No & No & Yes & Yes \\
Number of observations & No & Yes & No & Yes \\
Number of countries & 442 & 442 & 442 & 442 \\
$R^{2}$ & 30 & 30 & 30 & 30 \\
\hline
\end{tabular}

Notes: Robust standard errors in parentheses. Significance levels: ${ }^{*} p<0.1,{ }^{* *} p<0.05,{ }^{* * *} p<0.01$. Informality is measured as the log of the hidden production as a share of GDP (in \%). Labor productivity is measured as GDP per hour worked in 2010 USD.

In a next step we also include as explanatory variables, the average tax rates on labor and capital for 15 countries in the period 1999-2007. This empirical exercise identifies the relation between productivity and informality after controlling for differences in taxes and their evolution over time in the same spirit as in the quantitative analysis in the previous section. Table 5 shows the results (specifications (1)-(4)). The impact of the productivity on informality and evasion is still negative and significant. Moreover, in all specifications the magnitude of the estimated coefficient is larger than before (when we did not control for taxes). ${ }^{32}$ Interestingly, the elasticity of the size of informal economy with respect to labor productivity in our quantitative model is of smaller magnitude. Recall that observed labor productivity in Bulgaria increased around $48 \%$ over the period 2000-2014. At the same time the reduction in informality in the model when only productivity is present is 7.68 percentage points which is a reduction of around $20 \%$ (see Table 3 ). This implies an elasticity of informal economy size with respect to productivity of around 0.405 . The fact that the cross-country empirical analysis also implies a large role of productivity for the decrease in informality is reassuring. In a final set of exercises, we also control for the quality of governance too (Table 5, specifications (5)-(6)). Results do not change dramatically relative to the previous specifications. Note that the signs of the estimated coefficients become negative and significant when we control for country fixed effects in specifications (4) and (6). This might be an indication that within countries and over time taxes are set high whenever informality is on its way down.

Validation across Sectors. Figure 16 plots the average size of informal activity and two measures of labor productivity by the sectors for the Bulgarian economy for the period 2000-2008. The message is clear: sectors with low productivity (such as agriculture) have high level of informality. The opposite is true for manufacturing and services.

In Table 6, we relate informality and productivity using a panel dataset on sectoral level for Bulgaria in 20002008. The three sectors are again agriculture, manufacturing and services. The negative association between the 
two variable is still present and it is even stronger when we control for sector fixed effects. Thus, the empirical exercise confirms the basic results in obtained by the quantitative analysis in the previous section.

Table 5: Informality and labor productivity across countries and over time, 1999-2013.

\begin{tabular}{|c|c|c|c|c|c|c|}
\hline & \multicolumn{6}{|c|}{ Dependent variable: Informality } \\
\hline & (1) & (2) & (3) & (4) & (5) & (6) \\
\hline Output per hour worked & $\begin{array}{l}-0.786^{* *} \\
(0.279)\end{array}$ & $\begin{array}{l}-1.014^{* * *} \\
(0.121)\end{array}$ & $\begin{array}{l}-1.007^{* * * *} \\
(0.233)\end{array}$ & $\begin{array}{l}-1.207^{* * *} \\
(0.116)\end{array}$ & $\begin{array}{l}-0.727^{* * *} \\
(0.241)\end{array}$ & $\begin{array}{l}-1.378^{* * * *} \\
(0.126)\end{array}$ \\
\hline Labor tax rate & & & $\begin{array}{l}1.591 \\
(0.957)\end{array}$ & $\begin{array}{l}-1.416^{* * *} \\
(0.388)\end{array}$ & $\begin{array}{l}1.523^{*} \\
(0.841)\end{array}$ & $\begin{array}{l}-1.248^{*} \\
(0.599)\end{array}$ \\
\hline Capital tax rate & & & $\begin{array}{l}0.164 \\
(0.675)\end{array}$ & $\begin{array}{l}-0.631^{* * *} \\
(0.151)\end{array}$ & $\begin{array}{l}0.304 \\
(0.602)\end{array}$ & $\begin{array}{l}-0.661^{* * *} \\
(0.180)\end{array}$ \\
\hline Government quality & & & & & $\begin{array}{l}-1.757^{* * *} \\
(0.545)\end{array}$ & $\begin{array}{l}0.064 \\
(0.0753)\end{array}$ \\
\hline Country fixed effects & No & Yes & No & Yes & No & Yes \\
\hline Number of observations & 131 & 131 & 126 & 126 & 102 & 102 \\
\hline Number of countries & 15 & 15 & 15 & 15 & 15 & 15 \\
\hline$R^{2}$ & 0.236 & 0.545 & 0.379 & 0.700 & 0.598 & 0.723 \\
\hline
\end{tabular}

Notes: Robust standard errors in parentheses. Significance levels: ${ }^{*} p<0.1,{ }^{* *} p<0.05,{ }^{* * *} p<0.01$. Informality is measured as the log of hidden production as a share of GDP (in \%). Labor productivity is measured as GDP per hours worked in 2010 USD. Tax rates are taken from Trabandt and Uhlig (2011). The index of government quality comes from the WB-WGI database.
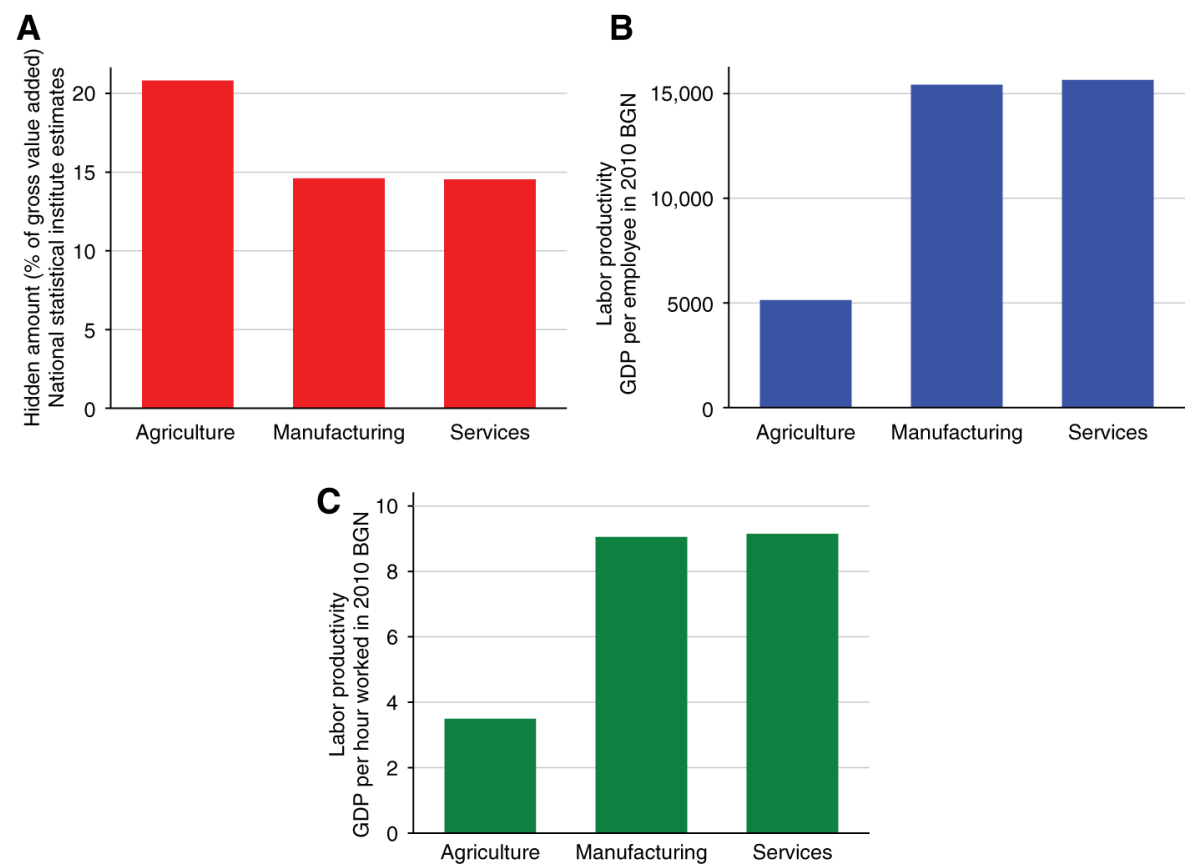

Figure 16: Informality and labor productivity by sectors, Bulgaria 2000-2008 averages.

(A) Informality (B) Output per Hour Worked (C) Output per Employee

Notes: Informality in a sector is measured as the hidden production as a share of sector-level gross value added (in \%). Output per worker and output per hour worked in a sector are measured in 2010 BGN. Data comes from the National Statistical Institute. The estimated informal economy size by sectors is much lower than the numbers of Schneider and Enste (2013).

\section{Optimal taxation}

What are the optimal taxes in this economy? What we have in mind is a benevolent government which maximizes average welfare by choosing tax schedules for personal and business income subject to collecting at least as much revenue as in the baseline model economy. In this exercise, we allow employers and employees to adjust their behavior with respect to hiding production in response to the imposed tax levels. The optimal taxation exercise is performed for the year of 2014. We use the estimated true productivity for this year along with 
information on minimum wages and social contributions. In addition, we impose that tax revenue should be at least as much as in the 2014 baseline economy. Corporate taxes are proportional, while the considered personal income tax schedules are restricted to the functional form for average tax rates, $1-\alpha y^{-\tau}$, where $y$ is taxable income. Essentially, the government makes a decision on the corporate income tax rate, $t_{E}$, the average tax rate for personal income, $1-\alpha$, and the level of progressivity, $\tau$. ${ }^{33}$

Table 6: Relationship between informality and labor productivity using sector-level data, Bulgaria 2000-2008.

\begin{tabular}{lllll}
\hline \multicolumn{4}{l}{ Dependent variable: Informality } & \\
\cline { 2 - 5 } & $\mathbf{( 1 )}$ & $\mathbf{( 2 )}$ & $\mathbf{( 3 )}$ & $\mathbf{( 4 )}$ \\
\hline Output per worker & $-0.349^{* * *}$ & $-0.787^{* * *}$ & & $-0.675^{*}$ \\
Output per hour worked & $(0.034)$ & $(0.354)$ & $-0.399^{* * *}$ & $(0.356)$ \\
Sector fixed effects & & & $(0.037)$ & Yes \\
Number of observations & No & Yes & No & 27 \\
Number of sectors & 27 & 27 & 3 & 3 \\
$R^{2}$ & 3 & 3 & 0.536 & 0.135 \\
\hline
\end{tabular}

Notes: Robust standard errors in parentheses. Significance levels: ${ }^{*} p<0.1,{ }^{* *} p<0.05,{ }^{* * *} p<0.01$. Sectors: Agriculture, Manufacturing, and Services. Informality in a sector is measured as the log of the hidden production as a share of sector-level gross value added (in \%).

Output per worker and output per hour worked in a sector are measured in 2010 BGN.

People in our economy are risk-neutral and all output is consumed. Therefore, the welfare criterion boils down to the level of total production. ${ }^{34}$ The government solves Ramsey-type problem of the following type,

$$
\max _{\left\{\alpha, \tau, t_{E}\right\}} \hat{Y}+H \equiv Y-L
$$

subject to identities (25)-(28) which define the objective function, and

$$
\int\left[T_{E}\left(e^{* *}(z \lambda)-S_{E}\left(w^{* *}(z \lambda)\right)\right)+T_{W}\left(w^{* *}(z \lambda)-S_{W}\left(w^{* *}(z \lambda)\right)\right)\right] d F(\lambda) \geq \bar{T}
$$

with corporate taxes levied on an island of productivity $\lambda$ given by

$$
T_{E}\left(e^{* *}(z \lambda)-S_{E}\left(w^{* *}(z \lambda)\right)\right)=t_{E}\left(e^{* *}(z \lambda)-S_{E}\left(w^{* *}(z \lambda)\right)\right)
$$

and personal income taxes given by

$$
T_{W}\left(w^{* *}(z \lambda)-S_{W}\left(w^{* *}(z \lambda)\right)\right)=\left(w^{* *}(z \lambda)-S_{W}\left(w^{* *}(z \lambda)\right)\right)-\alpha\left(w^{* *}(z \lambda)-S_{W}\left(w^{* *}(z \lambda)\right)\right)^{1-\tau} .
$$

In words, the total level of production in the economy is maximized with respect to the tax parameters $\left\{\alpha, \tau, t_{E}\right\}$. The constraint (31) states that the tax revenue collected across all productive islands amounts at least to the taxes raised in the baseline economy, $\bar{T}$. The expressions (32) and (33) introduce the parametric forms of the tax schedules. Note that when optimizing over the tax parameters, the government faces the optimal reaction of workers and employers to taxes encoded into the functions $e^{* *}(\cdot)$ and $w^{* *}(\cdot)$ for reported income from Section 3.3.

The results of the optimization exercise are summarized in Table 7. To minimize the loss of production due to evasion the government should shift the tax burden from corporate income to labor income. In particular, it should cut the corporate tax rate from $10 \%$ to $9 \%$, while at the same time it should increase the average tax rate on workers from $10 \%$ to around $29 \%$. The informal economy size, and thus, tax evasion is responsive to changes to the corporate tax but does not react to changes in the personal income taxes. This is so because the bargaining power is shifted almost entirely to the employers. As a consequence, minimizing productive efficiency due to evasion calls for a lower corporate tax. Then, personal income tax is set to a high level in order to generate the necessary tax revenue.

The optimal tax progressivity is summarized in the parameter $\tau=-0.003$, a very mild form of regressivity. Therefore, we can conclude that redistribution through taxing personal income does not play any major role in 
shaping the optimal tax code. The personal income schedule essentially consists of a proportional rate of $29 \%$. Recall that around a quarter of all workers in the baseline economy receive minimum wages. These workers are located at the lower end of the island-specific productivity distribution. Ideally, many of these islands would have reported wages that are even lower than the minimum if wages were not constrained from below. In this case, hidden output would have increased even further. In this context, cutting taxes for low wage earners is not diminishing hidden output because the majority of these earners would not alter their reporting behavior in the presence of redistribution. On the other hand, taxing income of workers on more productive islands at a higher rate would increase the incentives of tax evasion..$^{35}$

Table 7: Optimal taxation.

\begin{tabular}{lrr}
\hline & Baseline & Optimal taxes \\
\hline Personal income taxes & & \\
Average tax rate, $1-\alpha$ & 0.10 & 0.29 \\
Tax Progressivity, $\tau$ & 0.00 & -0.003 \\
Corporate taxes & & 0.09 \\
Proportional rate, $t_{E}$ & 0.10 & 12375.69 \\
Objective function value & 12374.85 & \\
\hline
\end{tabular}

It is worth mentioning that the productive gains of implementing the optimal tax system are small relative to the case of the baseline economy, as shown on last row of Table 7. This implies that the optimal taxation economy does not differ significantly from the baseline economy in terms of aggregate statistics.

\section{Conclusions}

In this paper we evaluated the relative importance of labor productivity versus income taxes and social security contributions for tax compliance in an economy with a large degree of informality. The results from our quantitative exercise point out that informality in Bulgaria is largely irresponsive to changes in the personal income tax, whereas a non-negligible role is played by the corporate income tax. The main driver of the decline of informality is the rise in labor productivity, which accounts for more than three quarters of the decline in informality during the period under investigation.

Such findings call into question one of the main benefits argued in favor of a personal income flat tax reform. Hall and Rabushka (1995) claim that a sizable cut of top marginal tax rates would lead to higher tax revenues due to an increase in tax compliance. In an European setting, we find this might not be the case.

We envision two useful ways of extending the simple framework introduced in this paper. First, in the current analysis we abstract from life-cycle savings and pension benefits. This additional feature would make tax evasion less attractive because avoiding social contributions would reduce pension entitlements. We think, however, that this is not a quantitatively relevant margin for the economy under investigation. Bulgarian pension benefits are quite limited and the retirement age is very close to life-expectancy. ${ }^{36}$ Second, the introduction of decreasing returns to scale technology in the model would generate a meaningful notion of firm size, and hence, would allow us to explore the relationship between tax evasion, firm size and firm-level productivity. This additional structure would require the availability of very detailed matched employer-employee data. We leave these extensions to future research.

\section{Funding}

This research is supported by research grant RRC1437 from the CERGE-EI Foundation under a program of the Global Development Network.

\section{Notes}

1 We follow the definition of informal economic activity of the OECD: "all legal production activities that are deliberately concealed from public authorities for the following kind of reasons: to avoid payment of income, value added or other taxes; to avoid payment of social security contributions; to avoid having to meet certain legal standards such as minimum wages, maximum hours, safety or health standards, etc." Therefore, criminal activities and unpaid work are not considered as part of the informal economy. 
2 This fact is confirmed by both the estimates of Schneider and Enste (2013) which we utilize in the paper and by a recent report on the size of the shadow economy across the globe by the Association of Chartered Certified Accountants (Association of Chartered Certified Accountants 2017).

3 The relevant data is further discussed in Online Appendix A.1.

4 Following Slemrod and Yitzhaki (2002), we differentiate two types of tax noncompliance: tax evasion and tax avoidance. Tax evasion refers to the illegal misreporting of income. In contrast, tax avoidance refers to mostly legal actions taken by individuals or firms to reduce their tax liabilities. In this paper we focus exclusively on tax evasion as the source of informality.

5 The fact that production units with higher productivity and/or size face a higher cost of evasion is confirmed by a host of empirical evidence in European countries. Among others, using data from the Italian Revenue Agency (IRA) Bobbio (2016) documents for Italy that firms with lower turnover evade significantly more.

6 The theoretical literature on tax evasion starts with Allingham and Sandmo (1972) who present a stylized model of tax evasion by a risk-averse agent who faces the probability of getting caught and penalized by the tax authorities. For a detailed summary of the existing literature, see Slemrod and Yitzhaki (2002).

7 The share of firms formally registred when they started operations in the country is as high as $97 \%$ in Bulgaria, $96 \%$ In Romania, 95.6 in Hungary, $98 \%$ in Poland, etc. Data on the share of formally registered firms are taken from the 2013 World Bank Enterprise Survey. See Table A.2 in Online Appendix A.1 for more details. This evidence is also surveyed in Williams (2008) who writes that "[in Eastern Europe] most undeclared work is conducted by formal enterprises which under-report their earnings rather than by wholly undeclared enterprises". 8 A subset of the authors study this channel in Di Nola et al. (2018).

9 An important dimension of the tax system which is left out here is the value-added tax of $20 \%$. This rate did not change in the period under consideration. Therefore, this indirect method of taxation is unlikely to play a role when it comes to changes in informality and tax evasion.

10 We use popular commercial accounting software to derive tax rates at a very fine grid of income which goes up to 100 times the average wage in each year for the period 2000-2014. For more details, see Online Appendix A.2.

11 The mean of the ratio of minimum wage to average wage for full-time workers in Eastern Europe is 0.3 in 2000 and increases to 0.38 in 2014. The corresponding Western European values are 0.49 in 2000 and 0.43 in 2014. Relevant data comes from OECD Statistics and can be found here.

12 Here is the link to the statements of the finance minister. The number of employed people is taken from the National Statistical Institute and can be found here.

13 This assumption reflects the low labor mobility in Bulgaria. Even though detailed firm-level is not present to back up this assumption, the very low regional mobility (see here) and the low levels of average wages are telling measures for its validity.

14 This implies that whenever employers are productive enough to pay at least the minimum wage to the workers and secure non-negative profits for themselves, they always go for production. For simplicity, for the rest of the exposition, we assume that islands are always active, i.e. the minimum productive capacity of employers is sufficiently high.

15 Hiding output from the government can be costly due to a number of reasons. Firstly, production may need to take place at night and/or double accounting practices may be costly in terms of time. Second, tax evasion practices may require bribing government officials.

16 The aggregate productivity $z$ is treated as a known parameter in the decision-making process that follows.

17 Here we ignore the ceilings on the social contribution payments.

18 We impose the assumption that there are no inactive islands for this graphical representation.

19 We abstract from the case of a binding minimum wage. In such instance, the tax parameters do not influence the sharing rules.

20 Here we use parameter values of the estimated version of the model for 2001, which will be presented in the next sections. The case of progressive taxation $(\tau>0)$ uses the estimated $\tau$ for 2001, while in the proportional tax case we substitute it with $\tau=0$. The island-specific productivity $\lambda$ is fixed at the median of the distribution $F$.

21 Keep in mind that an decrease in $\alpha$ implies higher average tax rates for personal income.

22 The share of hidden income out of total production on an island is $h / \hat{y}=h /(y-h-\kappa(h))$. When $h$ is constant but $y$ increases, then the ratio $h / \hat{y}$ rises too.

23 We assume no island is inactive in production.

24 Bulgarian tax authorities do not yet include an estimate of the undeclared production in the calculation of GDP.

25 In the analytical part of the paper, we use a concrete functional form for the tax schedule on personal income. Here we use the observed empirical tax schedule on personal income. The empirical difference between the two approaches is marginal given the almost perfect fit of the functional form to the data. The description of the tax data calculations is presented in Online Appendix A.2.

26 We use 10 grid points to approximate the distribution of $\lambda$. The discretization procedure takes the lowest and the highest grid points to be 5 standard deviations away from the mean of the distribution. This truncation of the discrete distribution of $\lambda$ from below is sufficient to rule out inactivity in the estimated version of the model.

27 This result hinges crucially on the estimated high value of the parameter $\gamma$ which summarizes the bargaining power of employers. We perform sensitivity analysis with respect to this parameter and find that in economies where workers have a higher bargaining power, this result can be quantitatively less relevant. See details on that in the next subsection.

28 In our model setting, the cost of tax evasion captures in a parsimonious way the effectiveness of tax enforcement and the quality of the tax administration. See Section 3.1 for a discussion about the cost of evasion function in our model environment.

29 This counterfactual exercise is to be interpreted as "What would happen in an economy which experiences the same tax and labor productivity changes of Bulgaria but which has a different labor market structure, with stronger labor unions?".

30 See the cross-sectional distribution of informality implied by the model in Figure 11A.

31 We use output per hour worked instead of output per worker because of better data availability.

32 The sample size here is much smaller because of the additional explanatory variables are not available for all countries/years.

33 Note that in the baseline economy in 2014, personal income taxes are proportional with a rate of $10 \%$. Therefore the implied tax function parameters are given by $\alpha=0.9$ and $\tau=0$.

34 Inactivity of certain islands is not observed in the baseline economy. Therefore, the production capacity in this economy is given by $Y$ $=z$. In the economy with optimal taxes which will be presented soon, all islands are active too. This implies that the production capacity with optimal taxes is also given by $Y=z$. Therefore, the maximization problem over total production $(\hat{Y}+H)$ implies that the lost output due to tax evasion $L$ is minimized.

35 Our model does not feature a labor supply decision. If introduced, this additional feature coupled with small income effects may also contribute to having no significant amount of progressivity in the optimal tax schedule for personal income. It can also call for a lower optimal average tax rate.

36 The average pension benefit is around $40 \%$ of the (already very low) net average wage in the 2000s. For further details, see Adascalitei (2015). 
Article Note: The paper was previously circulated as "Productivity, Taxation and Evasion: An Analysis of the Determinants of the Informal Economy". We are grateful to Philippe Aghion, Carlos Carrillo-Tudela, Marco Maffezzoli, Xavier Ragot, Stephanie Stantcheva, Colin Williams, Todor Yalamov and seminar participants at the GDN Regional Conference in Prague, the University of Konstanz, the Marie Curie/IAPP Informal Economy Conference in Sofia, the Summer School at Balkanski-Panitza Institute for Advanced Study (BPIAS), the T2M Conference in Lisbon (2017), the ZEW Public Finance Conference (2017) and the EEA Conference (2018) for insightful comments. Veronika Georgieva and Angelina Nazarova are thanked for providing excellent research assistance.

\section{References}

Adascalitei, Dragos. 2015. “From Austerity to Austerity: The Political Economy of Public Pension Reforms in Romania and Bulgaria." Social Policy \& Administration 51: 464-487.

Albrecht, James, Lucas Navarro, and Susan Vroman. 2009. “The Effects of Labour Market Policies in an Economy with an Informal Sector." The Economic Journal 119 (539): 1105-1129.

Allingham, Michael G., and Agnar Sandmo. 1972. "Income Tax Evasion: A Theoretical Analysis." Journal of Public Economics 1 (3): $323-338$.

Antunes, Antonio R., and Tiago V. de V. Cavalcanti. 2007. “Start up Costs, Limited Enforcement, and the Hidden Economy." European Economic Review 51 (1): 203-224.

Association of Chartered Certified Accountants. 2017. "Emerging from the Shadow: The Shadow Economy to 2025." Technical Report, The Association of Chartered Certified Accountants.

Benabou, Roland. 2002. "Tax and Education Policy in a Heterogeneous-Agent Economy: What Levels of Redistribution Maximize Growth and Efficiency?" Econometrica 70 (2): 481-517.

Bobbio, Emmanuele. 2016. “Tax Evasion, Firm Dynamics and Growth.” Questioni di Economia e Finanza (Occasional Papers) 357, Bank of Italy, Economic Research and International Relations Area.

Chen, Been-Lon. 2003. "Tax Evasion in a Model of Endogenous Crowth." Review of Economic Dynamics 6 (2): 381-403.

Di Nola, Alessandro, Ceorgi Kocharkov, Almuth Scholl, and Anna-Mariia Tkhir. 2018. “The Aggregate Consequences of Tax Evasion.” Working Paper Series of the Department of Economics, University of Konstanz 2018-06, Department of Economics, University of Konstanz.

Gorodnichenko, Yuriy, Jorge Martinez-Vazquez, and Klara Sabirianova Peter. 2009. "Myth and Reality of Flat Tax Reform: Micro Estimates of Tax Evasion Response and Welfare Effects in Russia." Journal of Political Economy 117 (3): 504-554.

Guner, Nezih, Remzi Kaygusuz, and Gustavo Ventura. 2014. "Income Taxation of U.S. Households: Facts and Parametric Estimates." Review of Economic Dynamics 17 (4): 559-581.

Hall, Robert E., and Alvin Rabushka. 1995. “The Flat Tax.” Hoover Institution.

Heathcote, Jonathan, Kjetil Storesletten, and Giovanni L. Violante. 2016 “Optimal Tax Progressivity: An Analytical Framework." Quarterly Journal of Economics 132: 1693-1754.

Joubert, Clement. 2015. “Pension Design with a Large Informal Labor Market: Evidence from Chile.” International Economic Review 56(2): 673694.

Kleven, Henrik Jacobsen, Martin B. Knudsen, Claus Thustrup Kreiner, Søren Pedersen, and Emmanuel Saez. 2011. “Unwilling or Unable to Cheat? Evidence From a Tax Audit Experiment in Denmark." Econometrica 79 (3): 651-692.

Koreshkova, Tatyana A.. 2006. "A Quantitative Analysis of Inflation as a Tax on the Underground Economy." Journal of Monetary Economics 53 (4): 773-796.

Kuehn, Zoe. 2014. “Tax Rates, Governance, and the Informal Economy in High-Income Countries.” Economic Inquiry 52 (1): $405-430$.

Lee, Bong-Soo, and Beth Fisher Ingram. 1991. "Simulation Estimation of Time-series Models." Journal of Econometrics 47 (2-3): $197-205$.

Maffezzoli, Marco. 2011. “Tax Evasion under Market Incompleteness." Working Papers 378, IGIER (Innocenzo Gasparini Institute for Economic Research), Bocconi University.

Meghir, Costas, Renata Narita, and Jean-Marc Robin. 2015. "Wages and Informality in Developing Countries." American Economic Review 105 (4): 1509-1546.

Orsi, Renzo, Davide Raggi, and Francesco Turino. 2014. “Size, Trend, and Policy Implications of the Underground Economy.” Review of Economic Dynamics 17 (3): 417-436.

Pappa, Evi, Rana Sajedi, and Eugenia Vella. 2015. “Fiscal Consolidation with Tax Evasion and Corruption." Journal of International Economics 96: S56-S75.

Pelek, Selin, and Cokce Uysal. 2016. "Envelope Wages, Underreporting and Tax Evasion: The Case of Turkey.".

Schneider, Friedrich. 2015. "Size and Development of the Shadow Economy of 31 European and 5 other OECD Countries from 2003 to 2015 : Different Developments." Technical Report, Johannes Kepler University.

Schneider, Friedrich, and Dominik H. Enste. 2013. The Shadow Economy: An International Survey. Cambridge University Press.

Slemrod, Joel, and Shlomo Yitzhaki. 2002. "Tax Avoidance, Evasion, and Administration." In Handbook of Public Economics, edited by A. J. Auerbach and M. Feldstein, chapter 22, 1423-1470. Vol. 3 of Handbook of Public Economics, Elsevier.

Tonin, Mirco. 2011. "Minimum Wage and Tax Evasion: Theory and Evidence." Journal of Public Economics 95 (11): 1635-1651.

Trabandt, Mathias, and Harald Uhlig. 2011. "The Laffer Curve Revisited." Journal of Monetary Economics 58 (4): 305-327.

Ulyssea, Gabriel. 2018. "Firms, Informality, and Development: Theory and Evidence from Brazil." American Economic Review 108 (8): $2015-$ 2047.

Williams, Colin C. 2008. “Envelope Wages in Central and Eastern Europe and the EU.” Post-Communist Economies 20 (3): 363-376. 
Williams, Colin C. 2014. "Explaining Cross-national Variations in the Prevalence of Envelope Wages: Some Lessons from a 2013 Eurobarometer Survey." Industrial Relations Journal 45 (6): 524-542.

Williams, Colin C., and Jo Padmore. 2013. “'Envelope Wages' in the European Union.” International Labour Review 152 (3-4): 411-430.

Supplementary Material: The online version of this article offers supplementary material (DOI: https://doi.org/10.1515/bejm-2018-0252). 